\title{
Surface and snowdrift sublimation at Princess Elisabeth station, East Antarctica
}

\author{
W. Thiery ${ }^{1}$, I. V. Gorodetskaya ${ }^{1}$, R. Bintanja ${ }^{2}$, N. P. M. Van Lipzig ${ }^{1}$, M. R. Van den Broeke ${ }^{3}$, C. H. Reijmer ${ }^{3}$, and \\ P. Kuipers Munneke ${ }^{3}$ \\ ${ }^{1}$ Department of Earth and Environmental Sciences, University of Leuven, Leuven, Belgium \\ ${ }^{2}$ KNMI (Royal Netherlands Meteorological Institute), De Bilt, The Netherlands \\ ${ }^{3}$ Institute for Marine and Atmospheric Research, Utrecht University, Utrecht, The Netherlands
}

Correspondence to: W. Thiery (wim.thiery@ees.kuleuven.be)

Received: 27 February 2012 - Published in The Cryosphere Discuss.: 17 April 2012

Revised: 9 July 2012 - Accepted: 15 July 2012 - Published: 9 August 2012

\begin{abstract}
In the near-coastal regions of Antarctica, a significant fraction of the snow precipitating onto the surface is removed again through sublimation - either directly from the surface or from drifting snow particles. Meteorological observations from an Automatic Weather Station (AWS) near the Belgian research station Princess Elisabeth in Dronning Maud Land, East-Antarctica, are used to study surface and snowdrift sublimation and to assess their impacts on both the surface mass balance and the surface energy balance during 2009 and 2010. Comparison to three other AWSs in Dronning Maud Land with 11 to $13 \mathrm{yr}$ of observations shows that sublimation has a significant influence on the surface mass balance at katabatic locations by removing $10-23 \%$ of their total precipitation, but at the same time reveals anomalously low surface and snowdrift sublimation rates at Princess Elisabeth ( $17 \mathrm{~mm}$ w.e. $\mathrm{yr}^{-1}$ compared to $42 \mathrm{~mm}$ w.e. $\mathrm{yr}^{-1}$ at Svea Cross and $52 \mathrm{~mm}$ w.e. $\mathrm{yr}^{-1}$ at Wasa/Aboa). This anomaly is attributed to local topography, which shields the station from strong katabatic influence, and, therefore, on the one hand allows for a strong surface inversion to persist throughout most of the year and on the other hand causes a lower probability of occurrence of intermediately strong winds. This wind speed class turns out to contribute most to the total snowdrift sublimation mass flux, given its ability to lift a high number of particles while still allowing for considerable undersaturation.
\end{abstract}

\section{Introduction}

The surface mass balance (SMB) includes the input and/or removal of mass at the surface and hence constitutes an essential part of the total mass balance of glaciers and ice sheets. Consequently, its study is crucial for understanding the current and future evolution of the Antarctic ice sheet and associated sea-level changes. On a snow- or ice-covered surface, the SMB is given by

$\mathrm{SMB}=\mathrm{PR}+\mathrm{RU}+\mathrm{ER}_{\mathrm{ds}}+\mathrm{SU}_{\mathrm{s}}+\mathrm{SU}_{\mathrm{ds}}$

with the different terms of the SMB being total (solid and liquid) precipitation (PR), liquid water runoff (RU), erosion (deposition) due to divergence (convergence) of horizontal snowdrift transport $\left(\mathrm{ER}_{\mathrm{ds}}\right)$, surface sublimation (deposition) $\left(\mathrm{SU}_{\mathrm{s}}\right)$ and sublimation of drifting snow particles within a column extending from the surface to the top of the drifting snow layer $\left(\mathrm{SU}_{\mathrm{ds}}\right)$ (Van den Broeke et al., 2004a). Note that in this definition, each term is defined negative when it removes mass from the surface.

As surface sublimation depends on near-surface temperature, the process is marked by a strong seasonality (Takahashi et al., 1994; Bintanja and Van den Broeke, 1995; Reijmer and Oerlemans, 2002; Frezzotti et al., 2004). In addition, the process is characterised by a strong spatial variability: in the extremely cold interior of the Antarctic ice sheet, $\mathrm{SU}_{\mathrm{S}}$ is virtually absent (Déry and Yau, 2002), whereas blue ice areas are associated with high sublimation rates (e.g. at Seal rock in the Sør Rondane mountains, Takahashi et al. (1992) recorded $\mathrm{SU}_{\mathrm{s}}$ rates from -200 to $-280 \mathrm{~mm}$ w.e. $\mathrm{yr}^{-1}$ over a blue ice area). 
Whenever the friction velocity $\left(u_{*}\right)$ becomes sufficiently high for the drag force to overcome inter-particle bonding forces and gravity, snow particles are lifted from the surface to form "drifting snow" (Bintanja, 1998). Snowdrift is a very common phenomenon in Antarctica: over certain parts of the ice sheet, snowdrift events have been observed on approximately one out of four days (Mann, 1998), and in the extremely windy Cape Denison, Terre Adélie (Wendler et al., 1997), snowdrift is even observed most of the year (Budd et al., 1966; Schwerdtfeger, 1984). During snowdrift events, continuous sublimation of the floating snow particles takes place, as the ambient air is usually undersaturated with respect to ice (Schmidt, 1982). Continuous ventilation of the floating particle thereby significantly enhances the transfer of moisture from the particle to the surrounding air (Bintanja, 1998). In addition, water vapour exchange takes place on all sides of each particle. Thus, snowdrift sublimation $\left(\mathrm{SU}_{\mathrm{ds}}\right)-$ whenever it occurs - is more effective in ablating mass per unit of time than $\mathrm{SU}_{\mathrm{s}}$ (Van den Broeke et al., 2004a; Bintanja, 1998). From a model study, Déry and Yau (2002) concluded that, on the scale of the Antarctic ice sheet, $\mathrm{SU}_{\mathrm{ds}}$ removed $15.32 \mathrm{~mm}$ w.e. $\mathrm{yr}^{-1}$ on average from 1979 to 1993. Although this average appears small compared to continental scale values for the net SMB (149-171 mm w.e. $\mathrm{yr}^{-1}$; Vaughan et al., 1999; Van Lipzig et al., 2002b; Van de Berg et al., 2006), it masks a tremendous spatial variation, with virtually nonexistent $\mathrm{SU}_{\mathrm{ds}}$ in the interior of Antarctica to one of the major contributions near the relatively warm and windy coast (Bintanja, 1998; Déry and Yau, 2002).

In addition to the decrease in upward turbulent momentum flux, $\mathrm{SU}_{\mathrm{ds}}$ constitutes a source of water vapour and a sink of sensible heat in the air (Déry and Taylor, 1996; Bintanja, 2001b). In fact, sublimation of floating snow particles tends to saturate the entire surface layer, starting in the lowest levels and therewith inhibiting further sublimation (Bintanja, 2001a). From the large number of numerical models for snowdrift sublimation and transport that have been developed over the last two decades (Pomeroy et al., 1993; Mobbs and Dover, 1993; Uematsu, 1993; Déry and Yau, 1999; Gallée, 1998; Liston and Sturm, 1998; Mann, 1998; Essery et al., 1999; Bintanja, 2000c; Liston and Elder, 2006; Lenaerts et al., 2010), several succeed in reproducing this self-limiting nature of snowdrift sublimation (Xiao et al., 2000).

In contrast, observing the different components of the SMB in Antarctica poses huge challenges. While precipitation measurements are disturbed by snowdrift, and SMB monitoring, using for instance stakes, requires reliable snow density measurements, it is nearly impossible to measure $\mathrm{SU}_{\mathrm{s}}, \mathrm{SU}_{\mathrm{ds}}$ and $\mathrm{ER}_{\mathrm{ds}}$ directly. The Automatic Weather Station (AWS) program in Dronning Maud Land coordinated by the Institute for Marine and Atmospheric Research of Utrecht University (IMAU), aims to tackle these problems by collecting high-quality meteorological observations which allow the calculation of the SMB components. In February 2009, this program was extended by installing AWS 16 near the Belgian Antarctic station Princess Elisabeth (http: //ees.kuleuven.be/hydrant). Data collected at this new station are valuable, not only because they fill a vast observational gap spanning over $1070 \mathrm{~km}$ between the coastal stations Novolazarevskaya $\left(70^{\circ} 46^{\prime} \mathrm{S} ; 11^{\circ} 50^{\prime} \mathrm{E}\right)$ and Syowa $\left(69^{\circ} 00^{\prime} \mathrm{S}\right.$; $39^{\circ} 35^{\prime} \mathrm{E}$ ), but even more as the station is located in a specific microtopographical setting, i.e. close to a mountain range.

The two main goals of this study are (i) to compare sublimation rates calculated from AWS 16 to other, existing time series in Dronning Maud Land and (ii) to understand the observed differences from a physical perspective. In order to achieve this, first surface sublimation and snowdrift sublimation were calculated for four AWSs, followed by an assessment of their relative contribution to the SMB. Next, the magnitude of the latent heat flux (LHF) in relation to other surface energy balance (SEB) components is investigated through application of a SEB model developed for snow-covered terrain (Van den Broeke et al., 2005). Finally, a sensitivity analysis was conducted to find the meteorological variables controlling $\mathrm{SU}_{\mathrm{s}}$ and $\mathrm{SU}_{\mathrm{ds}}$. Combined with the study of the near-surface meteorology, these findings allow to attribute the sublimation anomaly at Princess Elisabeth.

\section{Data and methods}

\subsection{AWS data}

AWS 16 was deployed in the valley down Gunnestadbreen glacier, $300 \mathrm{~m}$ east of Utsteinen ridge $\left(71^{\circ} 57^{\prime} \mathrm{S} ; 23^{\circ} 21^{\prime} \mathrm{E}\right)$ at the foot of the Sør Rondane mountains in the escarpment zone (Fig. 1). The Utsteinen ridge - oriented in a north-south direction and with an altitude of $1420 \mathrm{~m}$ a.s.l. - is $700 \mathrm{~m}$ long, a few meters wide and protrudes around $20 \mathrm{~m}$ above the surrounding snow surface (Gorodetskaya et al., 2010; Pattyn et al., 2009). Since February 2009, Utsteinen ridge hosts the Belgian scientific base Princess Elisabeth (Fig. 1b). The area is influenced both by cyclones that bring in heat and moisture from the warmer regions surrounding Antarctica and katabatic winds advecting cold air from the interior of the Antarctic Ice Sheet (Gorodetskaya et al., 2012).

AWS 5 is situated near the Antarctic stations Wasa and Aboa, on the coastal slopes of the ice sheet, just inland of the grounding line. AWS 6 at Svea Cross stands at the foot of the Heimefront Mountains and is strongly influenced by katabatic winds. Finally, AWS 9 is located a few kilometres east of the German Antarctic station Kohnen, on Amundsenisen on the East Antarctic plateau (Van den Broeke et al., 2004a). AWS characteristics are listed in Table 1.

Each AWS records air temperature $(T)$, pressure $(p)$, wind speed $(u)$ and direction (WD), relative humidity with respect to water (RH) and down- and upward short- and long-wave radiation fluxes $\left(\mathrm{SW}_{\mathrm{in}}, \mathrm{SW}_{\text {out }}, \mathrm{LW}_{\mathrm{in}}, \mathrm{LW}_{\text {out }}\right)$ at a single level, initially about $4 \mathrm{~m}$ above the surface (Gorodetskaya et al., 2010; Van den Broeke et al., 2004a). In addition, the distance 
Table 1. AWS characteristics. *: values from Van den Broeke et al. (2004a) for 1998-2001. The snow density at AWS 16 was retrieved from the first $85 \mathrm{~cm}$ of an ice core drilled in February 2009 near the station. Start and end of observation mark the first respectively last entry used in this study; all stations except AWS 6 are still operational. Also, note that AWS 16 has no lower bound for the mass balance since no mast extension has been conducted yet.

\begin{tabular}{|c|c|c|c|c|}
\hline & AWS 16 & AWS 5 & AWS 6 & AWS 9 \\
\hline \multicolumn{5}{|l|}{ Location } \\
\hline Nearby station & Princess Elisabeth & Wasa/Aboa & Svea Cross & Kohnen \\
\hline Latitude & $71^{\circ} 57^{\prime} \mathrm{S}$ & $73^{\circ} 06^{\prime} 19^{\prime \prime} \mathrm{S}$ & $74^{\circ} 28^{\prime} 53^{\prime \prime} \mathrm{S}$ & $75^{\circ} 00^{\prime} 41^{\prime \prime} \mathrm{S}$ \\
\hline Longitude & $23^{\circ} 21^{\prime} \mathrm{E}$ & $13^{\circ} 09^{\prime} 53^{\prime \prime} \mathrm{W}$ & $11^{\circ} 31^{\prime} 06^{\prime \prime} \mathrm{W}$ & $00^{\circ} 00^{\prime} 44^{\prime \prime} \mathrm{E}$ \\
\hline Altitude (m a.s.1.) & 1420 & 363 & 1160 & 2892 \\
\hline \multicolumn{5}{|l|}{ Setup of this study } \\
\hline Start of observation & 3 Feb 2009 & 3 Feb 1998 & 3 Feb 1998 & 3 Feb 1998 \\
\hline Start of hourly observation & 12 Jan 2010 & 2 Feb 2003 & 9 Jan 2004 & 13 Jan 2001 \\
\hline End of observation & 2 Feb 2011 & 2 Feb 2011 & 2 Feb 2009 & 2 Feb 2011 \\
\hline Snow density $\left(\mathrm{kg} \mathrm{m}^{3}\right)$ & 336 & $383^{*}$ & $396^{*}$ & $307^{*}$ \\
\hline Mass balance cap (mm w.e.) & / & -150 & -100 & -200 \\
\hline \multicolumn{5}{|c|}{ Meteorological means, observation period } \\
\hline$T(\mathrm{~K})$ & 254 & 257 & 253 & 231 \\
\hline $\mathrm{RH}_{i}(\%)$ & 56 & 80 & 75 & 89 \\
\hline$u\left(\mathrm{~m} \mathrm{~s}^{-1}\right)$ & 5.0 & 6.7 & 6.8 & 4.4 \\
\hline
\end{tabular}

between the surface and the $T$ and RH measurement level $(H)$ is monitored by a sonic height ranger. Sensor specifications are shown in Table 2 . Where possible, the analysis is conducted on hourly resolution; else, 2-hourly values are used as model input (Table 1). Finally, observed RH values are converted to relative humidity with respect to ice $\left(\mathrm{RH}_{i}\right)$ similar to Anderson (1994).

While 13-yr time series are used for AWS 5 and 9, and $11 \mathrm{yr}$ for AWS 6, currently only $2 \mathrm{yr}$ of measurements are available for AWS 16, from 3 February 2009 until 2 February 2011. Observation periods are listed in Table 1 and, unless stated otherwise, results are presented for the respective periods of data availability. Obviously, a 2-yr time series is insufficient to determine a reliable climatology or seasonal cycle of the station's mass and energy fluxes. Moreover, data gaps in December 2009 and November 2010 might cause a bias towards winter values; especially for the summer phenomenon surface sublimation this might be an issue. However, although analysis of longer time series might be useful to reduce the uncertainties of estimates presented below, results indicate features which cannot be ascribed to data or model uncertainty.

\subsection{Sublimation and SMB}

The in-situ measurements are used to dissect the net accumulation signal at each station into its components following the method described by Van den Broeke et al. (2004a). The core of this SMB model builds on the findings from MoninObukhov similarity theory to calculate surface sublimation, while snowdrift sublimation is retrieved through averaging three different parameterisations for snowdrift sublimation. Details of the method are given below.

Surface sublimation $\mathrm{SU}_{\mathrm{s}}\left(\mathrm{kg} \mathrm{m}^{-2} \mathrm{~s}^{-1}\right)$ can be obtained from the surface latent heat flux LHF $\left(\mathrm{W} \mathrm{m}^{-2}\right)$ using the relationship $\mathrm{SU}_{\mathrm{s}}=\mathrm{LHF} / \mathrm{L}_{\mathrm{sub}}$, where $\mathrm{L}_{\mathrm{sub}}=2.84 \times 10^{6} \mathrm{~J} \mathrm{~kg}^{-1}$ is the constant latent heat release associated with the sublimation process (assumed constant). The surface latent heat flux LHF can be expressed as

$\mathrm{LHF}=\rho_{\mathrm{air}} \mathrm{L}_{\mathrm{sub}} u_{*} q_{*}$

where $u_{*}\left(\mathrm{~m} \mathrm{~s}^{-1}\right)$ and $q_{*}\left(\mathrm{~kg} \mathrm{~kg}^{-1}\right)$ the turbulent scaling parameters of momentum and moisture and $\rho_{\text {air }}\left(\mathrm{kg} \mathrm{m}^{-3}\right)$ the density of the near-surface air (the latter retrieved using the ideal gas law). Together with the turbulent scaling parameter of heat $\theta_{*}(\mathrm{~K}), u_{*}$ and $q_{*}$ can be determined based on the "bulk" method (Denby and Greuell, 2000), i.e. through the flux-profile relationships:

$u_{*} \cong \frac{\kappa\left[u\left(z_{\mathrm{V}}\right)-u\left(z_{0, \mathrm{~V}}\right)\right]}{\ln \left(\frac{z_{\mathrm{V}}}{z_{0, \mathrm{~V}}}\right)-\Psi_{\mathrm{m}}\left(\frac{z_{\mathrm{V}}}{L_{\mathrm{MO}}}\right)}$

$\theta_{*} \cong \frac{\kappa\left[\theta\left(z_{T}\right)-\theta\left(z_{0, T}\right)\right]}{\ln \left(\frac{z_{T}}{z_{0, T}}\right)-\Psi_{\mathrm{h}}\left(\frac{z_{T}}{L_{\mathrm{MO}}}\right)}$

$q_{*} \cong \frac{\kappa\left[q\left(z_{q}\right)-q\left(z_{0, q}\right)\right]}{\ln \left(\frac{z_{q}}{z_{0, q}}\right)-\Psi_{\mathrm{h}}\left(\frac{z_{q}}{L_{\mathrm{MO}}}\right)}$ 
Table 2. AWS sensor specifications (EADT: estimated accuracy of daily totals) (http://ees.kuleuven.be/hydrant/). All four AWSs used in this study are similar in design.

\begin{tabular}{llll}
\hline Sensor & Type & Range & Accuracy \\
\hline Air pressure & Vaisala PTB101B & $600-1060 \mathrm{hPa}$ & $4 \mathrm{hPa}$ \\
Air temperature & Vaisala HMP35AC & -80 to $+56^{\circ} \mathrm{C}$ & $0.3^{\circ} \mathrm{C}$ \\
Relative humidity & Vaisala HMP35AC & $0-100 \%$ & $2-3 \%$ \\
Wind speed & Young 05103 & $0-60 \mathrm{~m} \mathrm{~s}^{-1}$ & $0.3 \mathrm{~m} \mathrm{~s}^{-1}$ \\
Wind direction & Young 05103 & $0-360^{\circ}$ & $3{ }^{\circ} \mathrm{C}$ \\
Pyranometer & Kipp and Zonen CNR1 & $305-2800 \mathrm{~nm}$ & $10 \%$ EADT \\
Pyrradiometer & Kipp and Zonen CNR1 & $5000-50000 \mathrm{~nm}$ & $10 \%$ EADT \\
Sonic height ranger & Campbell SR50 & $0.5-10 \mathrm{~m}$ & $0.01 \mathrm{~m}$ or 0.4\% \\
\hline
\end{tabular}

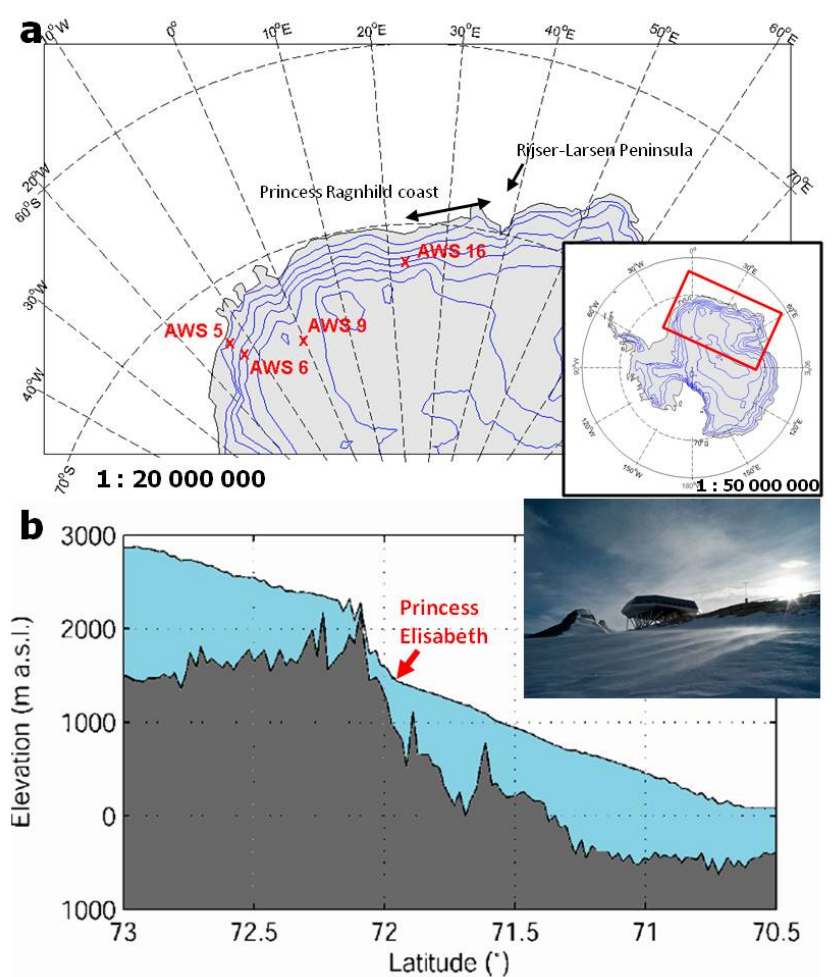

Fig. 1. (a) Map with focus on Dronning Maud Land, indicating the location of the 4 automatic weather stations (AWSs) under consideration. $500 \mathrm{~m}$ height contours are depicted in blue (http://www. eos.ubc.ca/ $\sim$ rich/map.html). (b) Surface (Bamber et al., 2009) and bedrock (Lythe and Vaughan, 2001) topographic transect along the $23^{\circ}$ E meridian (adapted from Pattyn et al., 2009). The outcropping bedrock at $\sim 72.1^{\circ} \mathrm{S}$ form the Sør Rondane mountains. Inset: snowdrift event at Princess Elisabeth, where AWS 16 is located.

with $\kappa=0.4$ the von Kármán constant, $u\left(z_{\mathrm{V}}\right)\left(\mathrm{m} \mathrm{s}^{-1}\right)$ the wind speed measured by the AWS at a height $z \mathrm{~V}$ above the surface and $u\left(z_{0, \mathrm{~V}}\right)$ the velocity at the surface. Mutatis mutandis, Eqs. (4) and (5) require values for the potential temperature $\theta(\mathrm{K})$ and the specific humidity $q\left(\mathrm{~kg} \mathrm{~kg}^{-1}\right)$, each at a level $z_{T}\left(z_{q}\right)$ above the surface and at the height of the temperature (moisture) roughness lengths $z_{0, T}\left(z_{0, q}\right) . \Psi_{\mathrm{m}}$ and
$\Psi_{\mathrm{h}}$ are the momentum and heat/moisture stability functions, respectively. $\mathrm{RH}_{i}$ and $T$ are measured at the same level, so $z_{T}=z_{q}=H$. Wind speed is measured about $0.75 \mathrm{~m}$ higher $\left(z_{V}=H+0.75 \mathrm{~m}\right)$. In our SMB calculations we adopted a value of $0.1 \mathrm{~mm}$ for the momentum surface roughness length $z_{0, \mathrm{~V}}$ (Bintanja, 2000d). Following the method developed by Andreas (1987), $z_{0, \mathrm{~V}}$ is related to $z_{0, T}$ and $z_{0, q}$ through two empirical expressions depending on the roughness Reynolds number $\operatorname{Re}_{*}=u_{*} z_{0, \mathrm{~V}} / \nu_{\text {air }}$, with $\nu_{\text {air }}$ the kinematic viscosity of air $\left(\mathrm{m}^{2} \mathrm{~s}^{-1}\right)$. By definition, $u\left(z_{0, \mathrm{~V}}\right)=0$. Furthermore, $T_{\mathrm{s}}$ can be obtained from the Stephan-Boltzmann law: $T\left(z_{0, T}\right)=$ $T_{\mathrm{s}}=\left(\mathrm{LW}_{\text {out }} / \varepsilon \sigma\right)^{1 / 4}$, with $\sigma=5.67 \times 10^{-8} \mathrm{~W} \mathrm{~m}^{-2} \mathrm{~K}^{-4}$ the Stephan-Boltzmann constant and the longwave emissivity $\varepsilon=1$. Subsequently, $\theta_{\mathrm{s}}$ can be derived. The value for $q\left(z_{0, q}\right)$ is calculated from the saturation vapour pressure with respect to ice $e_{\mathrm{s}, \mathrm{i}}$ at the surface (Curry and Webster, 1999), assuming the snow surface to be saturated with respect to ice. Note that, therewith, the near-surface $\mathrm{RH}_{i}$-gradient is assumed negative or zero at all times. Finally, the momentum and heat/moisture stability functions $\Psi_{\mathrm{m}}$ and $\Psi_{\mathrm{h}}$ are calculated using the expressions proposed by Holtslag and de Bruin (1988) for stable and very stable conditions, while equations put forward by Dyer (1974) are applied for the unstable regime. The ratio $z / L_{\mathrm{MO}}$ is used to discern between the three regimes: if $z / L_{\mathrm{MO}}>0.5$ conditions are very stable, $0.5>z / z L_{\mathrm{MO}}>0$ stands for stable conditions and $z / L_{\mathrm{MO}}<0$ represents unstable conditions. In each case, $L_{\mathrm{MO}}(\mathrm{m})$ stands for the Obukhov length scale, which can be calculated following (Van den Broeke et al., 2004a):

$L_{\mathrm{MO}}=\frac{u_{*}^{2}}{\kappa \frac{g}{\theta}\left(\theta_{*}+0.62 \theta q_{*}\right)}$.

Thus the problem is implicit, and requires iterative solving. Convergence $(<0.001 \%$ difference $)$ is usually reached after $10-15$ iterations.

Although the threshold friction velocity for snow transport depends on numerous environmental conditions such as temperature (Li and Pomeroy, 1997) and snow-pack properties, such as snow particle size and density (Gallée et al., 2001), snow transport was set to occur only when $u_{*}>0.3 \mathrm{~m} \mathrm{~s}^{-1}$. 
In that case, $\mathrm{SU}_{\mathrm{s}}$ is assumed to vanish and column-integrated snowdrift sublimation $\mathrm{SU}_{\mathrm{ds}}$ is estimated as the average of three parameterisations: Bintanja and Reijmer (2001), Déry and Yau (2001) and Bintanja (1998) (hereafter referred to as BR01, DY01 and B98, respectively).

The expressions put forward by BR01 account for the increase in $z_{0, \mathrm{~V}}, z_{0, T}$ and $z_{0, q}$ due to enhanced momentum dissipation, lower temperature and increased saturation levels, respectively, during snowdrift (Schmidt, 1986; Wamser and Lykossov, 1995; Mann et al., 2000; Bintanja, 2000b). BR01 suggest three empirical expressions depending on $u_{*}$ to account for the respective roughness length dependency upon wind speed, subsequently yielding $\mathrm{SU}_{\mathrm{ds}}$ in a way similar as described above. As the parameterisation is found to be no longer valid at wind speeds with corresponding friction velocities above $1 \mathrm{~m} \mathrm{~s}^{-1}$, a cap of $0.1 \mathrm{~m}$ on the momentum, heat and moisture roughness lengths was introduced.

On the basis of multiple integrations with the numerical blowing snow model PIEKTUK-D, DY01 derived another explicit parameterisation for snowdrift sublimation requiring the input of $u$ at $10 \mathrm{~m}$ above the surface, and $T$ and $\mathrm{RH}_{i}$ at $2 \mathrm{~m}$. For the latter two, observed values were used without applying any correction, whereas the $10 \mathrm{~m}$ wind speed was retrieved from the flux profile relationships neglecting stability effects and adopting $z_{0, \mathrm{~V}}=1 \mathrm{~mm}$. The latter follows DY01 and mirrors the roughness length increase during snowdrift. Note also that this value reasonably agrees with the mean increased roughness lengths parameterised by BR01 for each station $(0.64 \mathrm{~mm}, 0.87 \mathrm{~mm}, 1.2 \mathrm{~mm}$ and $1.8 \mathrm{~mm}$ at AWS 9, 16, 6 and 5, respectively).

Finally, B98 derived an expression for vertically integrated snowdrift sublimation from a set of simulations with the numerical blowing snow model SNOWSTORM forced with $3 \mathrm{~m} u$ and $T$. Since the B98 parameterisation was developed for application to AWS data for which no humidity measurements were available, $\mathrm{RH}_{i}$ was assumed constant and set to $70 \%$. However, judging from the $\mathrm{RH}_{i}$ values observed at AWS 5, 6, 9 and 16, this would lead to an overestimation of column snowdrift sublimation. Therefore, a linear rescaling of the form

$\mathrm{SU}_{\mathrm{ds}}=\mathrm{SU}_{\mathrm{ds}}\left(\frac{1-\mathrm{RH}_{i}}{1-0.7}\right)$

was applied in order to account for the variations in humidity.

The surface mass balance can be obtained by multiplying snow height changes with the snow density $\rho$ (Table 1 ). Given the density fluctuations observed in the upper snow layers at AWS 16, the uncertainty in the instantaneous surface mass balance is estimated to amount up to $\sim 15 \%$. Finally, the "residual term" containing PR and $\mathrm{ER}_{\mathrm{ds}}$ can be obtained from Eq. (1). Note that first, the raw snow height data had to be corrected for false reflections and mast extensions, the former using a histogram approach, the latter by imposing an upper limit to the accumulation (Table 1).

\subsection{SEB model}

Considering a skin layer, the surface energy balance (SEB) of a snow covered surface can be written as (Van den Broeke et al., 2005)

$$
\begin{aligned}
M & =\mathrm{SW}_{\text {in }}+\mathrm{SW}_{\text {out }}+\mathrm{LW}_{\text {in }}+\mathrm{LW}_{\text {out }}+\mathrm{SHF}+\mathrm{LHF}+G \\
& =R_{\mathrm{n}}+\mathrm{SHF}+\mathrm{LHF}+G
\end{aligned}
$$

with $M$ the amount of melt energy, $\mathrm{SW}_{\text {in }}$ and $\mathrm{SW}_{\text {out }}$ the incoming and outgoing shortwave radiative fluxes, $\mathrm{LW}_{\text {in }}$ and $\mathrm{LW}_{\text {out }}$ the incoming and outgoing longwave radiative fluxes, $R_{\mathrm{n}}$ the net radiation, SHF and LHF the sensible respectively latent heat flux and finally $G$ the subsurface conductive heat flux. All terms are in $\mathrm{W} \mathrm{m}^{-2}$ and defined positive when directed towards the surface.

With the goal of calculating the different components of the SEB, we use the SEB model described in detail by Van den Broeke et al. (2005) (for applications see Kuipers Munneke et al., 2009; van As et al., 2005; Giesen et al., 2008 and Van den Broeke et al., 2011). Here, we only provide a very short description of the model's main steps and assumptions. Essentially, AWS measurements $\left(\mathrm{SW}_{\mathrm{in}}, \mathrm{SW}_{\text {out }}, \mathrm{LW}_{\mathrm{in}}\right.$, $T$, RH, $u, p$ and $H$ ) serve as input to the model that iterates for a surface temperature $T_{\mathrm{s}}$ for which closure of all energy terms is achieved. An important advantage of this approach is that the observed $T_{\mathrm{S}}$ can be used to evaluate the model. Turbulent fluxes are determined analogous to the SMB model, whereas the subsurface conductive heat flux $G$ is obtained by extrapolating upwards the one-dimensional heat-transfer equation at 2 and $6 \mathrm{~cm}$ depth. Melting energy is determined from the excess energy whenever modelled $T_{\mathrm{s}}$ reaches the melting point. The initial $T_{\mathrm{S}}$ was chosen to minimise spinup effects (see also Van Lipzig et al., 2002a). The module calculating the subsurface SW radiation penetration (Brandt and Warren, 1993) is not used in our simulations, since it has been shown that its impact upon $T_{\mathrm{S}}$ both in Greenland and Antarctica is virtually inexistent (Kuipers Munneke et al., 2009; Brandt and Warren, 1993).

\section{Results}

\subsection{Model testing and evaluation}

Since the vertical $\mathrm{RH}_{i}$-gradient is assumed negative or zero (Sect. 2.2), one might expect similar gradients for $q$ assuming an isothermal stratification. However, even given this restriction, an important $T$-inversion might lead to a positive $q$-gradient or " $q$-inversion", as can be inferred from the Clausius-Clapeyron relationship. From Eq. (5), it can then be inferred that a $q$-inversion is always associated with a downward turbulent moisture flux. At low wind speeds, this leads to the prediction of surface deposition. If this happens during snowdrift however, BR01 will predict the deposition of mass rather than sublimation. But it is physically impossible 

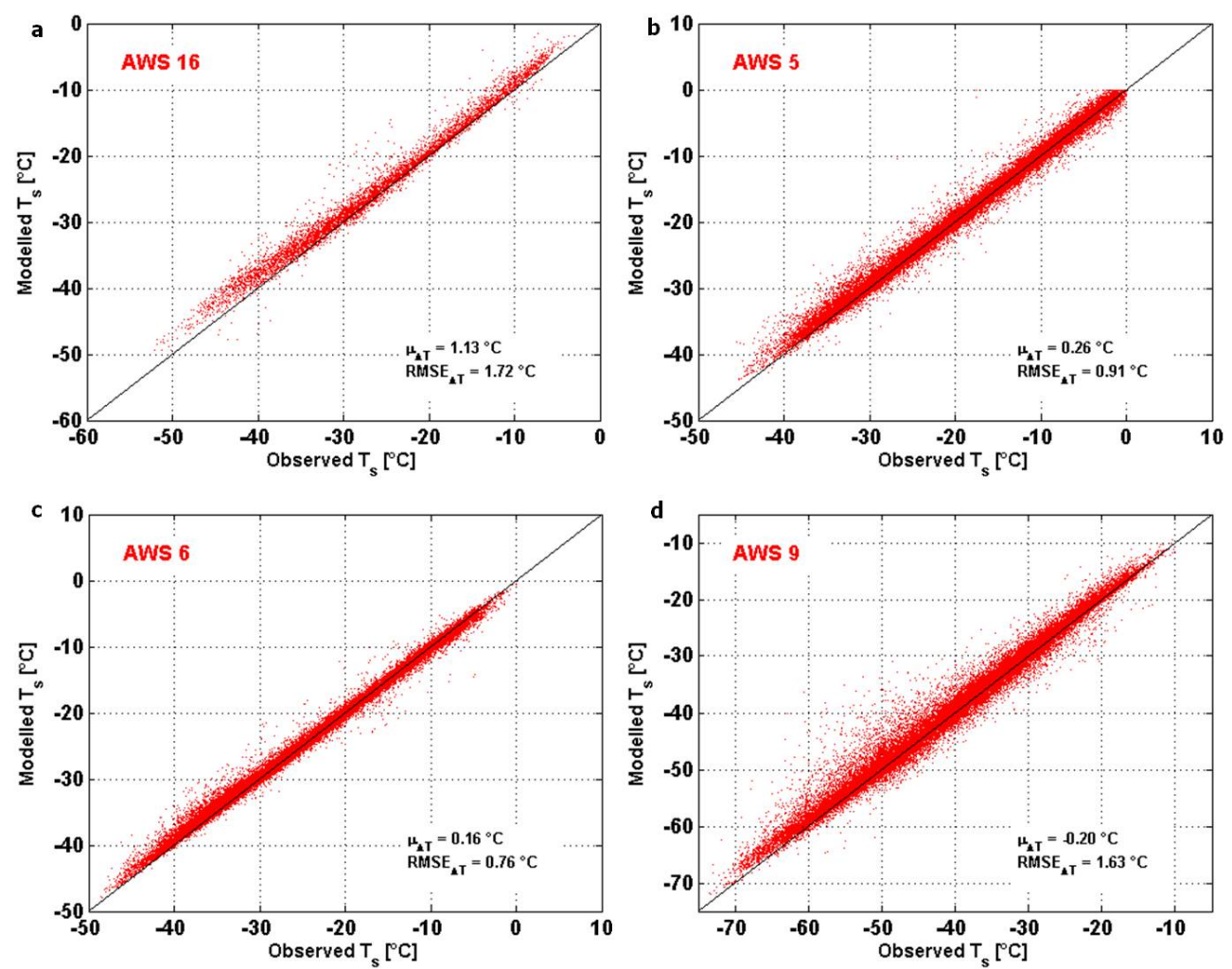

Fig. 2. Observed versus modelled surface temperature $T_{\mathrm{S}}$ (2 hour averages), varying time periods, at (a) AWS 16 - Princess Elisabeth, (b) AWS 5 - Wasa/Aboa, (c) AWS 6 - Svea Cross, and (d) AWS 9 - Kohnen. Note the different axes' ranges. $\mu_{\Delta T}$ presents the mean surface temperature difference and $\mathrm{RMSE}_{\Delta T}$ the root mean squared error of the surface temperature difference.

that the suspended particle accrete mass as long as the ambient air is not supersaturated. Moreover, DY01 and B98 do predict snowdrift sublimation rather than deposition during these events, as they do not depend upon the $q$-gradient but on a single-level $\mathrm{RH}_{i}$-value. While at AWS 5, 6 and 9 this situation is very rare, the micro-topography at Utsteinen ridge strongly favours the build-up of a $q$-inversion (Sect. 3.4.), forcing us to reject BR01 at AWS 16.

The SMB calculations are tested by applying the method to the first four years of available data for AWS 5, 6 and 9. Comparison with Van den Broeke et al. (2004a) shows that the model is successful in reproducing the SMB signal and the different components $\mathrm{SU}_{\mathrm{s}}$ and $\mathrm{SU}_{\mathrm{ds}}$, as differences are small and non-systematic. Hence it is appropriate to apply the SMB routine.

With the actual $T_{\mathrm{s}}$ directly derived from the observed $\mathrm{LW}_{\text {out }}$, the comparison of the modelled and observed $T_{\mathrm{S}}$ presents a powerful tool to evaluate the SEB model (Fig. 2). The overestimation of $T_{\mathrm{s}}$, which can be noted for very low $T_{\mathrm{S}}$, was found to coincide with clear sky conditions, suggesting that during these periods either the model performs less well, or the $\mathrm{LW}_{\text {in }}$ measurements are biased to lower values (Kuipers Munneke et al., 2009). However, in general, the good agreement between modelled and observed $T_{\mathrm{S}}$ indicates that the model is doing well, with a mean difference ranging from $0.16^{\circ} \mathrm{C}$ (AWS 16) to $1.13^{\circ} \mathrm{C}$ (AWS 5) and a RMSE from $0.76^{\circ} \mathrm{C}$ (AWS 6) to $1.72^{\circ} \mathrm{C}$ (AWS 16).

\subsection{Surface and snowdrift sublimation}

Table 3 depicts the SMB characteristics for the respective measurement periods. During the 2-yr measurement period, $\mathrm{SU}_{\mathrm{s}}$ removed $14 \mathrm{~mm}$ w.e. at AWS 16 . The signal shows a marked seasonality (Fig. 3a), with most of the sublimation taking place during summer. It also shows a continuous snow deposition during the winter of 2009. Surprisingly, $\mathrm{SU}_{\mathrm{s}}$ rates at AWS 5 and 6 ( -17 and $-20 \mathrm{~mm}$ w.e. $\mathrm{yr}^{-1}$, respectively) are two to three times larger than at AWS 16. In Sect. 3.4, we investigate reasons for this large difference. $\mathrm{SU}_{\mathrm{s}}$ attains it highest values in the katabatic wind zone, since with only $-3 \mathrm{~mm}$ w.e. $\mathrm{yr}^{-1}, \mathrm{SU}_{\mathrm{s}}$ is nearly absent at AWS 9 (Table 3). Using stake measurements at sites with reduced wind influence in Terre Adélie, Frezotti et al. (2004) have reported similar $\mathrm{SU}_{\mathrm{s}}$ gradients, with rates increasing from -3 to $-8 \mathrm{~mm}$ w.e. $\mathrm{yr}^{-1}$ on the Antarctic Plateau to $-42 \mathrm{~mm}$ w.e. $\mathrm{yr}^{-1}$ in the escarpment zone. In another study, Déry and Yau (2002) also predict a strong gradient for Dronning Maud Land, with $\mathrm{SU}_{\mathrm{s}}$ rates below $-5 \mathrm{~mm}$ w.e. $\mathrm{yr}^{-1}$ in the interior up to $-75 \mathrm{~mm}$ w.e. $\mathrm{yr}^{-1}$ at the grounding line. 

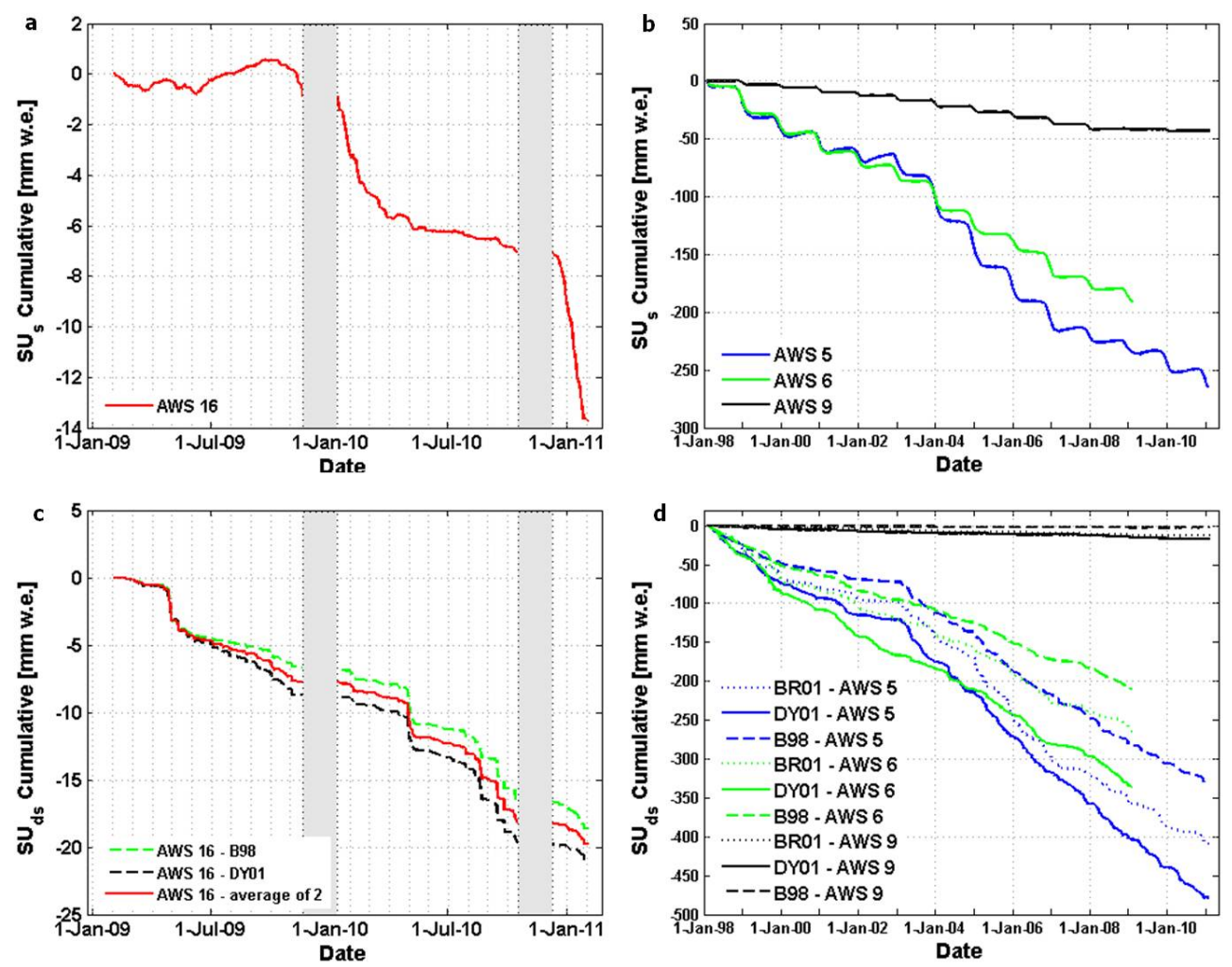

Fig. 3. Cumulative sublimation mass fluxes (mm w.e.): Surface sublimation $\mathrm{SU}_{\mathrm{S}}$ at (a) AWS 16 and (b) AWS 5, 6 and 9; Snowdrift sublimation $\mathrm{SU}_{\mathrm{ds}}$ at (c) AWS 16 and (d) AWS 5, 6 and 9.

At AWS 16, a marked difference between the first and second measurement year (hereafter referred to as 2009 and 2010, respectively) can be observed: in $2010, \mathrm{SU}_{\mathrm{s}}$ removed $11 \mathrm{~mm}$ w.e., compared to only $3 \mathrm{~mm}$ w.e. in 2009 . The second period coincides with lower saturation levels $(61 \%$ in 2009 compared to $52 \%$ in 2010), so one could state that the drier air opens a larger potential to sublimation during 2010. However, although the Spearman rank correlation $(\rho=-0.24)$ is significant at the $1 \%$ level, $\mathrm{RH}_{i}$ only explains $6 \%$ of the total variance in $\mathrm{SU}_{\mathrm{s}}$. Moreover, since surface deposition occurs at all values of $\mathrm{RH}_{i}$, this variable does not even allow for discrimination between sublimation and deposition. Instead, both the sign and magnitude of $\mathrm{SU}_{\mathrm{s}}$ predominantly depend upon the near-surface specific humidity gradient, represented by $q_{*}$ (Eq. 5), as demonstrated by a Spearman rank correlation of 0.88 , significant at the $1 \%$ level. For a near-surface $q$, decreasing with altitude surface sublimation takes place, while for a $q$-inversion surface deposition is to be expected. In Dronning Maud Land, $q$-inversions are formed when intrusions of warm, moist air encounter the cold Antarctic snow surface (Van den Broeke et al., 2004a).

The annual $\mathrm{SU}_{\mathrm{ds}}$ rate at AWS 16 is similar to $\mathrm{SU}_{\mathrm{s}}$ (Table 3), and removed $20 \mathrm{~mm}$ w.e. snow during the entire measurement period. Given the important uncertainties related to $\mathrm{SU}_{\mathrm{ds}}$ predictions, annual rates predicted by $\mathrm{B} 98$ and DY01 agree surprisingly well (Fig. 3c). A clear mark of season- ality is absent: we rather observe that an important fraction of the total $\mathrm{SU}_{\mathrm{ds}}$ mass flux is removed during circa 5 major events, coinciding with a decaying or developing cyclone (Gorodetskaya et al., 2012). Also here, $\mathrm{SU}_{\mathrm{ds}}$ is two to three times larger at AWS 5 and 6 and virtually inexistent at AWS 9. Even though, at AWS 9, snowdrift occurs about as often as at the other stations, air temperatures there are too low to generate sublimation from the suspended particles. The decrease in $\mathrm{SU}_{\mathrm{ds}}$ mass flux from coast to plateau has been reported in previous studies, notably by Bintanja (1998), who calculated rates to decrease from $-170 \mathrm{~mm}$ w.e. $\mathrm{yr}^{-1}$ at Dumont d'Urville, Terre Adélie, down to $-8 \mathrm{~mm}$ w.e. $\mathrm{yr}^{-1}$ on the plateau, and further by Déry and Yau (2002) and by Lenaerts and Van den Broeke (2012), who both predict significant $\mathrm{SU}_{\mathrm{ds}}$ mass fluxes near the grounding line in Dronning Maud Land ( -60 to $-80 \mathrm{~mm}$ w.e. $\mathrm{yr}^{-1}$ and -40 to $-70 \mathrm{~mm}$ w.e. $\mathrm{yr}^{-1}$, respectively), but no contribution $\left(<1 \mathrm{~mm}\right.$ w.e. $\left.\mathrm{yr}^{-1}\right)$ on the plateau.

The difference in sublimation rates between AWS 16 and the other katabatic stations remains significant, even when considering the short measurement period and the presence of data gaps. In fact, calculation of the sublimation mass fluxes for the 2009-2010 period at AWS 5 and 9 shows no strong change compared to their entire measurement period, suggesting that both years were not exceptional in terms of sublimation (Table 4). Furthermore, the effect of assuming 
Table 3. Comparison of specific surface mass balance and its components ( $\mathrm{mm}$ w.e. $\mathrm{yr}^{-1}$ ), and mean surface energy balance components $\left(\mathrm{W} \mathrm{m}^{-2}\right)$ at each station. The values at each station are valid for the respective measurement period at this station $(2,13,11$ and $13 \mathrm{yr}$ at AWS 16, 5, 6 and 9, respectively). As explained in the text, BR01 was not applied to AWS 16.

\begin{tabular}{|c|c|c|c|c|}
\hline & AWS 16 & AWS 5 & AWS 6 & AWS 9 \\
\hline Specific surface mass balance ( $\mathrm{mm}$ w.e. $\mathrm{yr}^{-1}$ ) & 149 & 174 & 256 & 71 \\
\hline Surface sublimation $\left(\mathrm{mm}\right.$ w.e. $\left.\mathrm{yr}^{-1}\right)$ & -7 & -20 & -17 & -3 \\
\hline Liquid water runoff ( $\mathrm{mm}$ w.e. $\mathrm{yr}^{-1}$ ) & 0 & 0 & 0 & 0 \\
\hline Snowdrift sublimation (mm w.e. $\mathrm{yr}^{-1}$ ) & -10 & -31 & -25 & -1 \\
\hline B98 (mm w.e. $\left.\mathrm{yr}^{-1}\right)$ & -9 & -25 & -19 & 0 \\
\hline BR01 (mm w.e. $\left.\mathrm{yr}^{-1}\right)$ & I & -31 & -24 & -1 \\
\hline DY01 (mm w.e. $\left.\mathrm{yr}^{-1}\right)$ & -10 & -37 & -31 & -1 \\
\hline Residual processes ( $\mathrm{mm}$ w.e. $\mathrm{yr}^{-1}$ ) & 166 & 226 & 298 & 75 \\
\hline Net radiation $\left(\mathrm{W} \mathrm{m}^{-2}\right)$ & -31 & -17 & -23 & -2 \\
\hline Sensible heat flux $\left(\mathrm{W} \mathrm{m}^{-2}\right)$ & 33 & 20 & 26 & 2 \\
\hline Latent heat flux $\left(\mathrm{W} \mathrm{m}^{-2}\right)$ & -2 & -3 & -3 & -1 \\
\hline Ground flux $\left(\mathrm{W} \mathrm{m}^{-2}\right)$ & -0.4 & 0.05 & -0.1 & -0.1 \\
\hline Melting energy $\left(\mathrm{W} \mathrm{m}^{-2}\right)$ & 0 & 0.02 & 0 & 0 \\
\hline
\end{tabular}
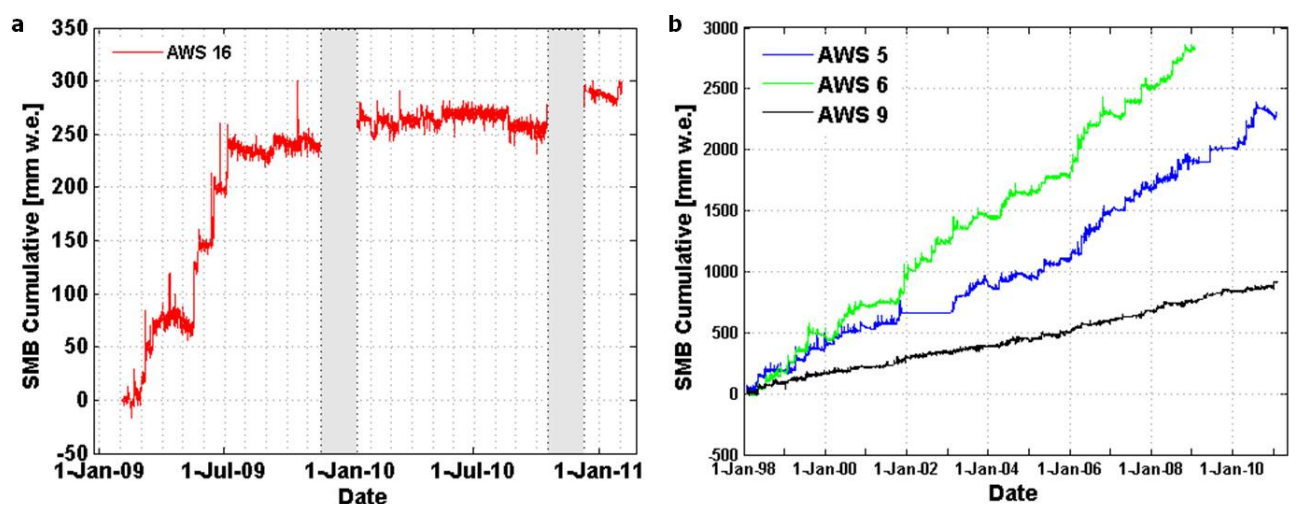

Fig. 4. Cumulative surface mass balance SMB (mm w.e.) for the respective measurement periods at (a) AWS 16 and (b) AWS 5, 6 and 9. Note that at AWS 16, accumulation during the December 2009 and November 2010 data gaps is captured by a jump in the snow height observations.

zero sublimation mass flux during data gaps can be investigated by estimating the mass loss due to sublimation during both data gaps at AWS 16. This is done by interpolating the mean $\mathrm{SU}_{\mathrm{s}}$ and $\mathrm{SU}_{\mathrm{ds}}$ rates in the month before and after each data gap, and indicates that $\mathrm{SU}_{\mathrm{s}}$ at AWS 16 might be $\sim 3 \mathrm{~mm}$ w.e. $\mathrm{yr}^{-1}$ stronger, while $\mathrm{SU}_{\mathrm{ds}}$ would increase with $\sim 2 \mathrm{~mm}$ w.e. $\mathrm{yr}^{-1}$ (Table 4). This effect is significant, but clearly not high enough to close the gap with the other katabatic stations.

\subsection{Contribution to SMB}

The surface mass balance at AWS 16 shows a net accumulation of $299 \mathrm{~mm}$ w.e. for the 2-yr measurement period corresponding to $149 \mathrm{~mm}$ w.e. $\mathrm{yr}^{-1}$ (Fig. 4a, Table 3). Note that even though this value lies within the net SMB range of 149$171 \mathrm{~mm}$ w.e. $\mathrm{yr}^{-1}$ computed for various time periods and av- eraged over the entire Antarctic ice sheet (Vaughan et al., 1999; Van Lipzig et al., 2002b; Van de Berg et al., 2006), it is lower than one would expect given its location relatively close to the coast. Of this increase of the snow height by about $0.89 \mathrm{~m}$, more than $80 \%(0.75 \mathrm{~m})$ was already achieved after the first year.

While the "residual processes" term obviously is the dominant component of the SMB (Table 3), estimation of the relative weight of PR and $\mathrm{ER}_{\mathrm{ds}}$ within this term is not straightforward. The sheltered location of AWS 16 might lead to a deceleration of winds and associated enhanced snowdrift deposition compared to an open area. However, a precise estimate of the wind contribution of $\mathrm{ER}_{\mathrm{ds}}$ at this particular site requires fluid dynamic modelling of snowdrift divergence/convergence including realistic topography and is beyond the scope of this study. Nonetheless, an attempt can be made to quantitatively constrain the magnitude of 

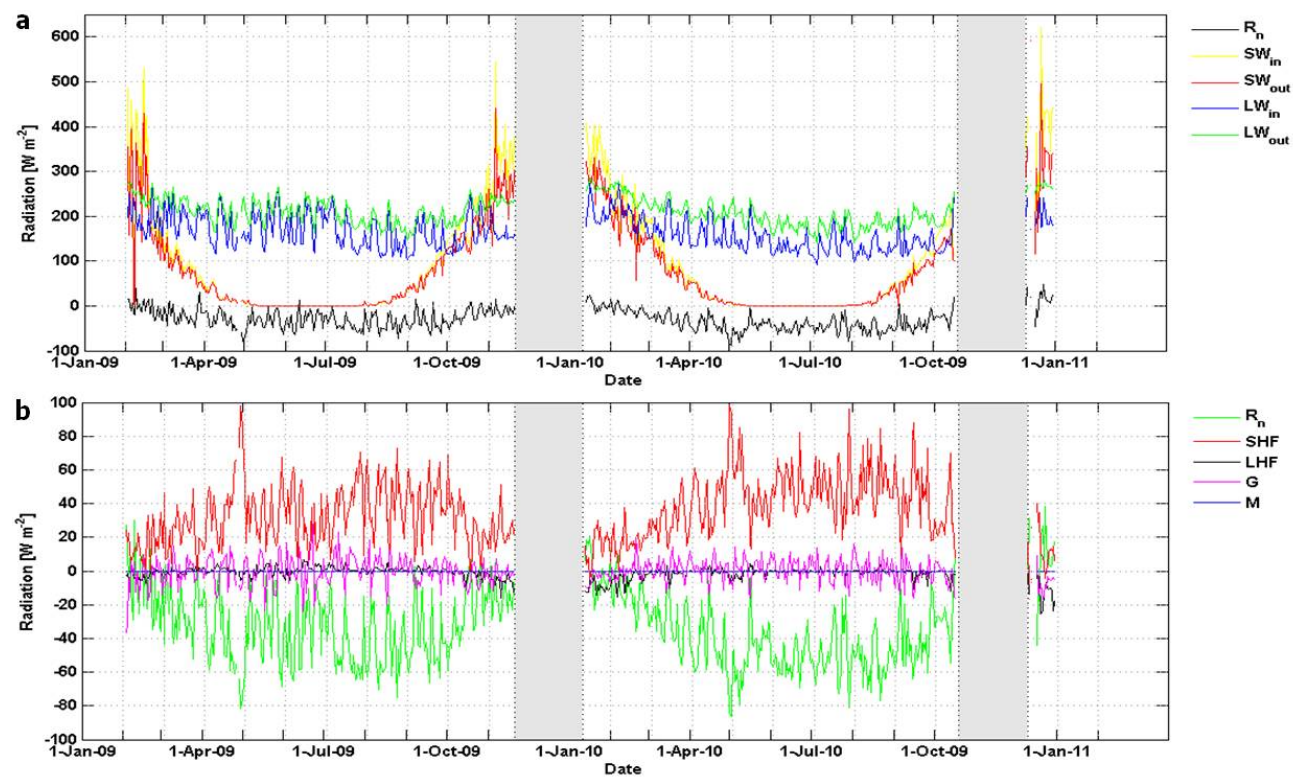

Fig. 5. Daily mean (a) net radiation $R_{n}$ and its components $\left(\mathrm{W} \mathrm{m}^{-2}\right.$ ), and (b) surface energy balance components (W m ${ }^{-2}$ ), 2009-2010, at AWS 16. Abbreviations stand for incoming (outgoing) shortwave (longwave) radiation ( $\mathrm{SW}_{\text {in }}, \mathrm{SW}_{\text {out }}, \mathrm{LW}_{\text {in }}, \mathrm{LW}_{\text {out }}, \mathrm{respectively}$ ), sensible heat flux SHF, latent heat flux LHF, subsurface conductive heat flux $G$ and melting energy $M$.

Table 4. Specific surface mass balance and its components (all units $\mathrm{mm}$ w.e. $\mathrm{yr}^{-1}$ ) at AWS 16, 5 and 9 for 2009-2010, with inclusion of $\mathrm{SU}_{\mathrm{s}}$ and $\mathrm{SU}_{\mathrm{ds}}$ estimates during the two data gaps at AWS 16. These estimates are computed by linearly interpolating mean sublimation rates in the month before and after each gap.

\begin{tabular}{lrrr}
\hline & AWS 16 & AWS 5 & AWS 9 \\
\hline Surface mass balance & 149 & 177 & 81 \\
Surface sublimation & -10 & -17 & -1 \\
Liquid water runoff & 0 & 0 & 0 \\
Snowdrift sublimation & -12 & -30 & -1 \\
Residual processes & 171 & 225 & 83 \\
\hline
\end{tabular}

$\mathrm{ER}_{\mathrm{ds}}$. Application of the parameterisation for snowdrift transport by Mann et al. (2000, see also Van Lipzig et al., 2004) to AWS 16 yields an estimate of $192 \mathrm{~mm}$ w.e. snow transported over the station during the measurement period $\left(96 \mathrm{~mm}\right.$ w.e. $\left.\mathrm{yr}^{-1}\right)$. This total transport term provides an upper bound for $\mathrm{ER}_{\mathrm{ds}}$, being the snow transport divergence, and which cannot be derived from single-point observations. There are good reasons to assume that the cumulative $\mathrm{ER}_{\mathrm{ds}}$ is much lower than the total snow transport: (i) suspended particles transported over the station contribute to the total snow transport but not to the SMB, and such particles are known to be transported over large distances in Antarctica (Déry et al., 1998); (ii) most probably, both erosion and deposition occur at the station during the course of time, therewith partially cancelling each other out; and (iii) modelling studies for Antarctica by Déry and Yau (2002), using re-analysis data, and Lenaerts and Van den Broeke (2012), using a coupled regional climate model, found much lower values for the cumulative $\mathrm{ER}_{\mathrm{ds}}$ mass flux $\left(0.05 \mathrm{~mm}\right.$ w.e. $\mathrm{yr}^{-1}$ for the latitudinal band $70^{\circ}-80^{\circ} \mathrm{S}$ and $\sim 10 \mathrm{~mm}$ w.e. $\mathrm{yr}^{-1}$ for the lee side of the Sør Rondane mountains, respectively). Hence, although we cannot completely rule out the contribution of $\mathrm{ER}_{\mathrm{ds}}$ to the residual term, hereafter it is considered negligible.

If this assumption is applied, it is found that PR is responsible for an accumulation of $332 \mathrm{~mm}$ w.e. at AWS 16 during the measurement period. With AWS 6 and 16 both situated at the foot of the steep transition towards the Antarctic Plateau ("the escarpment zone"), orographic forcing is a likely source for PR (Fig. 1). In agreement with observations in more inland stations, such as South Pole (Braaten, 2000), most of the accumulation at all AWSs occurs during sporadic precipitation events (Reijmer and Van den Broeke, 2003; Gorodetskaya et al., 2012). Comparison to a number of modelling studies, which compute long-term annual PR across the Antarctic ice sheet, reveals that the predictions of PR for the region around AWS 16 range from 100 to $300 \mathrm{~mm}$ w.e. $\mathrm{yr}^{-1}$ (Jaeger, 1976; Bromwich et al., 2004; Van den Broeke and Van Lipzig, 2004). Although the value calculated at AWS 16 for the 2-yr measurement period $\left(166 \mathrm{~mm}\right.$ w.e. $\left.\mathrm{yr}^{-1}\right)$ reasonably agrees with these estimates, it is noted that PR for each individual year (261 and $71 \mathrm{~mm}$ w.e. for 2009 and 2010, respectively) are both situated near the edge of this range. Further detailed discussion on the PR regime at AWS 16 and its relation to the atmospheric conditions is provided in Gorodetskaya et al. (2012). 

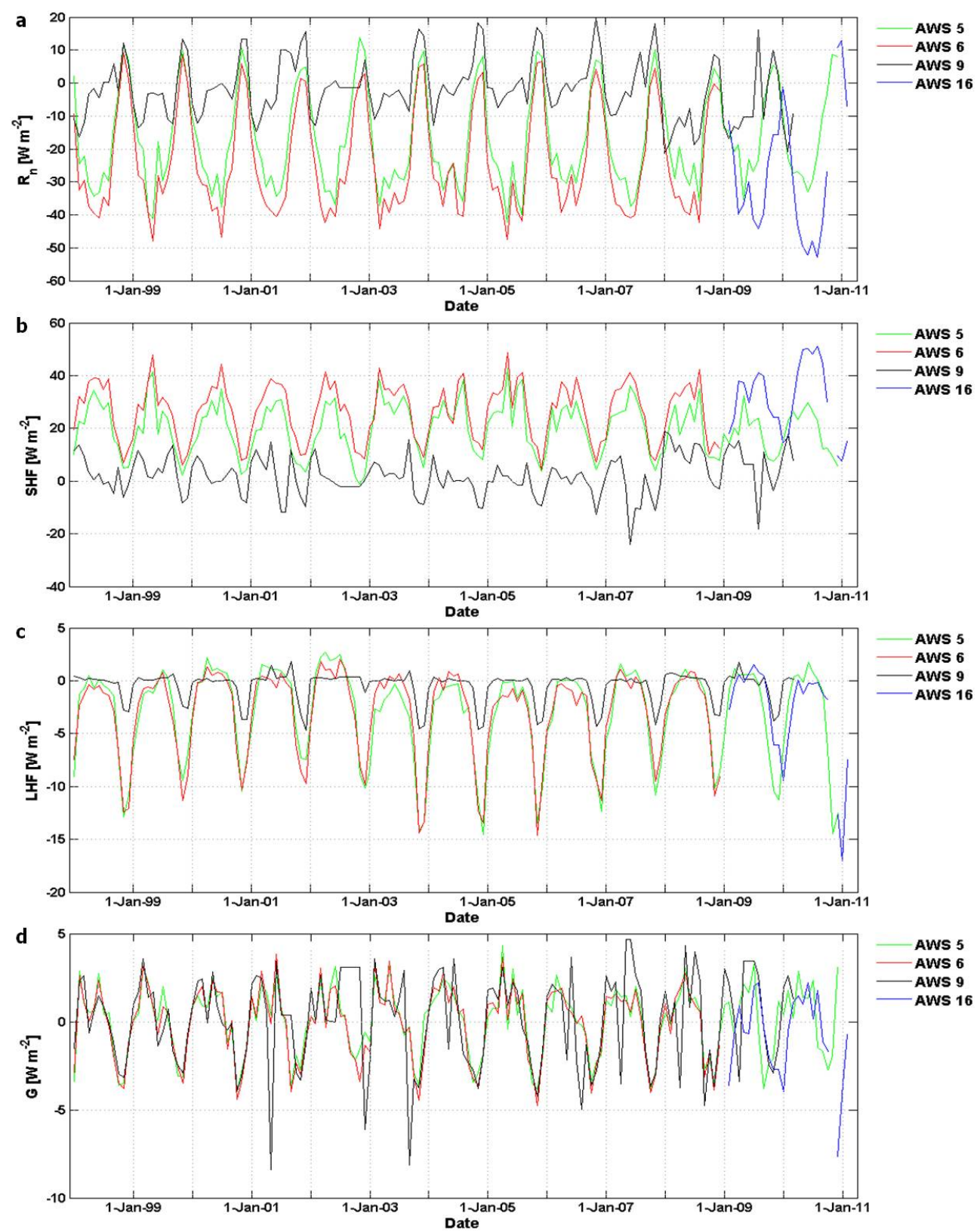

Fig. 6. Monthly mean surface energy balance components $\left(\mathrm{W} \mathrm{m}^{-2}\right)$ at AWS 5, 6, 9 and 16, respective measurement periods: (a) net radiation $R_{n}$, (b) sensible heat flux SHF, (c) latent heat flux LHF, (d) subsurface conductive heat flux $G$. Not shown is melting energy $M$, as this energy flux is absent at AWS 6, 9 and 16 and negligible at AWS 5.

Considering the entire measurement period, $\mathrm{SU}_{\mathrm{s}}$ and $\mathrm{SU}_{\mathrm{ds}}$ together removed $10 \%$ of all PR at AWS 16. The fractional removal increased from $4 \%$ in 2009 to $31 \%$ in 2010, indicating enhanced (summer) sublimation but especially limited accumulation during the second year at this location. This difference at AWS 16 is not found for the other stations. At AWS 5, 6 and 9, sublimation removed up to $23 \%, 14 \%$ and $6 \%$, respectively, of total precipitation during the respective measurement periods.

\subsection{Contribution to SEB}

Both $\mathrm{SW}_{\text {in }}$ and $\mathrm{SW}_{\text {out }}$ show a clear seasonal cycle (Fig. 5a). From around mid-May until mid-August, the sun does not rise anymore above Princess Elisabeth and both SW components drop to zero. Atmospheric scattering and cloud amount determine the final fraction reaching the surface, hence the small-scale variations in $\mathrm{SW}_{\text {in }}$. The high correlation between $\mathrm{SW}_{\text {in }}$ and $\mathrm{SW}_{\text {out }}$ (Spearman correlation coefficient $\rho=0.9975$, significant at the $1 \%$ level) underlines the high 


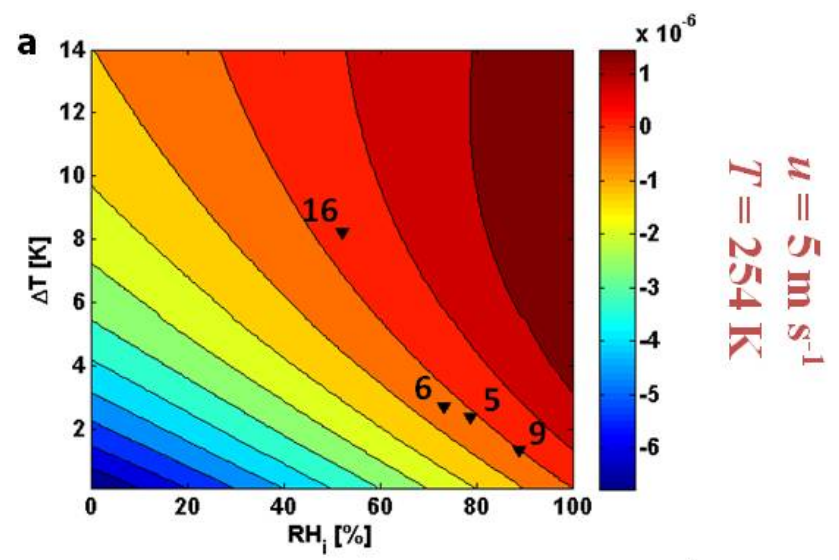

a radiation deficit during nearly the entire measurement period, except for the high summer.

At high latitudes and especially during winter, this radiative cooling of the surface may last the entire day and tends to render the near-surface air warmer than the underlying surface. As a response, the SHF transfers heat from near-surface air towards the surface (Fig. 5b) (Van Lipzig, 2007). It has been noted that this process causes increasing densities in near-surface air, and therewith leads to the formation of the katabatic wind system in the presence of a surface slope (Reijmer and Oerlemans, 2002). The LHF, representing the total amount of energy available for sublimation, is clearly less important in the SEB, except for high summer, when a clearly negative LHF consumes the $R_{\mathrm{n}}$ excess. The impact of $G$ on the energy budget is rather small, while $M$ is even completely absent at the station during the measurement period, consistent with observed $T_{\mathrm{s}}$ (Figs. 2a and 5b).

In Fig. 6a-d, monthly mean values of the different SEB components are depicted for the four AWSs. Compared to AWS 16, radiative losses are much smaller at AWS 9 but similar at AWS 5 and 6, with a maximum loss during wintertime when $\mathrm{SW}_{\text {in }}$ is absent and $\mathrm{LW}_{\text {in }}$ equilibrates towards the cloud base temperature (Van den Broeke et al., 2004b). Consequently, annual average positive SHF are larger at AWS 5, 6 and 16 and the seasonal cycle largely mirrors seasonal variations in $R_{\mathrm{n}}$ (Table 3, Fig. 6b). Again, compared to this balance, the LHF calculated by the SEB model are found to be much weaker except during high summer (Table 3, Fig. 6c).

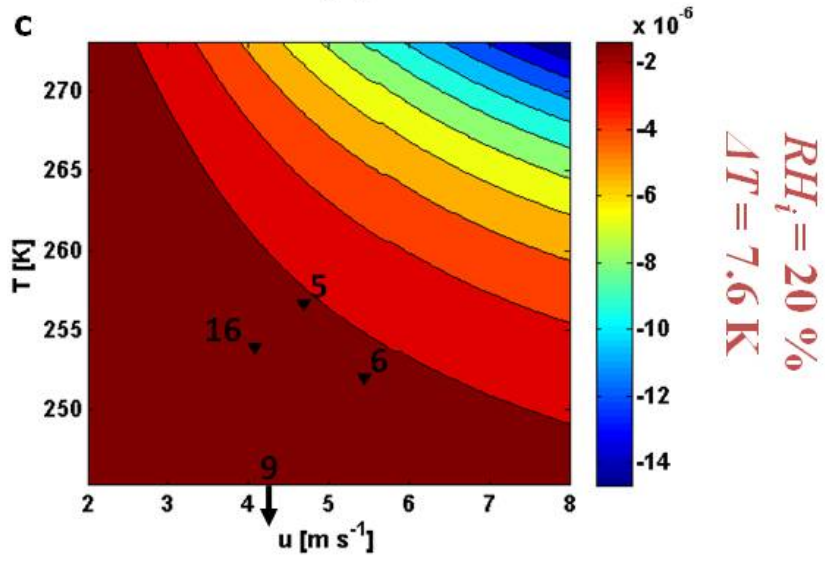

Fig. 7. $\mathrm{SU}_{\mathrm{s}}$ rates $\left(\mathrm{kg} \mathrm{m}^{-2} \mathrm{~s}^{-1}\right)$ from 3 sensitivity experiments, with (a) wind speed $u=5 \mathrm{~m} \mathrm{~s}^{-1}$ and air temperature $T=254 \mathrm{~K}$, (b) $u=5 \mathrm{~m} \mathrm{~s}^{-1}$ and surface temperature inversion $\Delta T=7.6 \mathrm{~K}$, and (c) relative humidity with respect to ice $\mathrm{RH}_{i}=20 \%$ and $\Delta T=7.6 \mathrm{~K}$. Mean values for $\mathrm{RH}_{i}, u$ and $\Delta T_{\mathrm{S}}$ were calculated for AWS 5, 6, 9 and 16 for snowdrift-free conditions and used to plot each station.

and relatively constant albedo $\alpha$ of the snow surface $(0.8<$ $\alpha<0.95$ ). As for the $\mathrm{LW}$ radiation components, a seasonal cycle is much less pronounced, and small scale fluctuations are stronger for $\mathrm{LW}_{\text {in }}$ compared to $\mathrm{LW}_{\text {out }}$ (Fig. 5a) given the stronger variations in the atmospheric emissivity caused by cloud cover variability. Overall, AWS 16 is characterised by

\subsection{Attributing the AWS 16 sublimation anomaly}

To account for the remarkably low sublimation rates at AWS 16 compared to other katabatic AWSs 5 and 6, one first needs to identify the main controlling variables for $\mathrm{SU}_{\mathrm{s}}$ and $\mathrm{SU}_{\mathrm{ds}}$. This was achieved through a number of sensitivity experiments, in which the values for $T, \mathrm{RH}_{i}, u$ and the magnitude of the near-surface temperature inversion $(\Delta T)$ were varied in pairs between bounds realistic for katabatic stations. For the parameters remaining constant during a given experiment, mean values at AWS 16 were used for snowdrift free or snowdrift conditions, respectively. As these four variables together constrain $q$ and $\Delta q$, and since the dependency of $\mathrm{SU}_{\mathrm{s}}$ upon $\Delta q$ is directly evident from Eqs. $(2,5)$, the latter variables need not to be tested. Figures 7 and 8 depict the most relevant of these experiments, together with the location of each station based on the mean meteorological state during snowdrift free and snowdrift conditions, respectively.

From Fig. 7a, it can be inferred that $\mathrm{SU}_{\mathrm{s}}$ predominantly depends upon $\Delta T$ : a strong inversion dampens thermal turbulence and therewith $\mathrm{SU}_{\mathrm{s}}$. Also $\mathrm{RH}_{i}$ is an important determinant. For instance, taking the AWS 16's mean wind velocity and temperature inversion, it is found that for $\mathrm{RH}_{i}$ values below $\sim 50 \%$, sublimation takes place, while deposition occurs at higher values (Fig. 7b). $T$ and $u$ are equally important, but only represent second order effects by allowing for a higher 

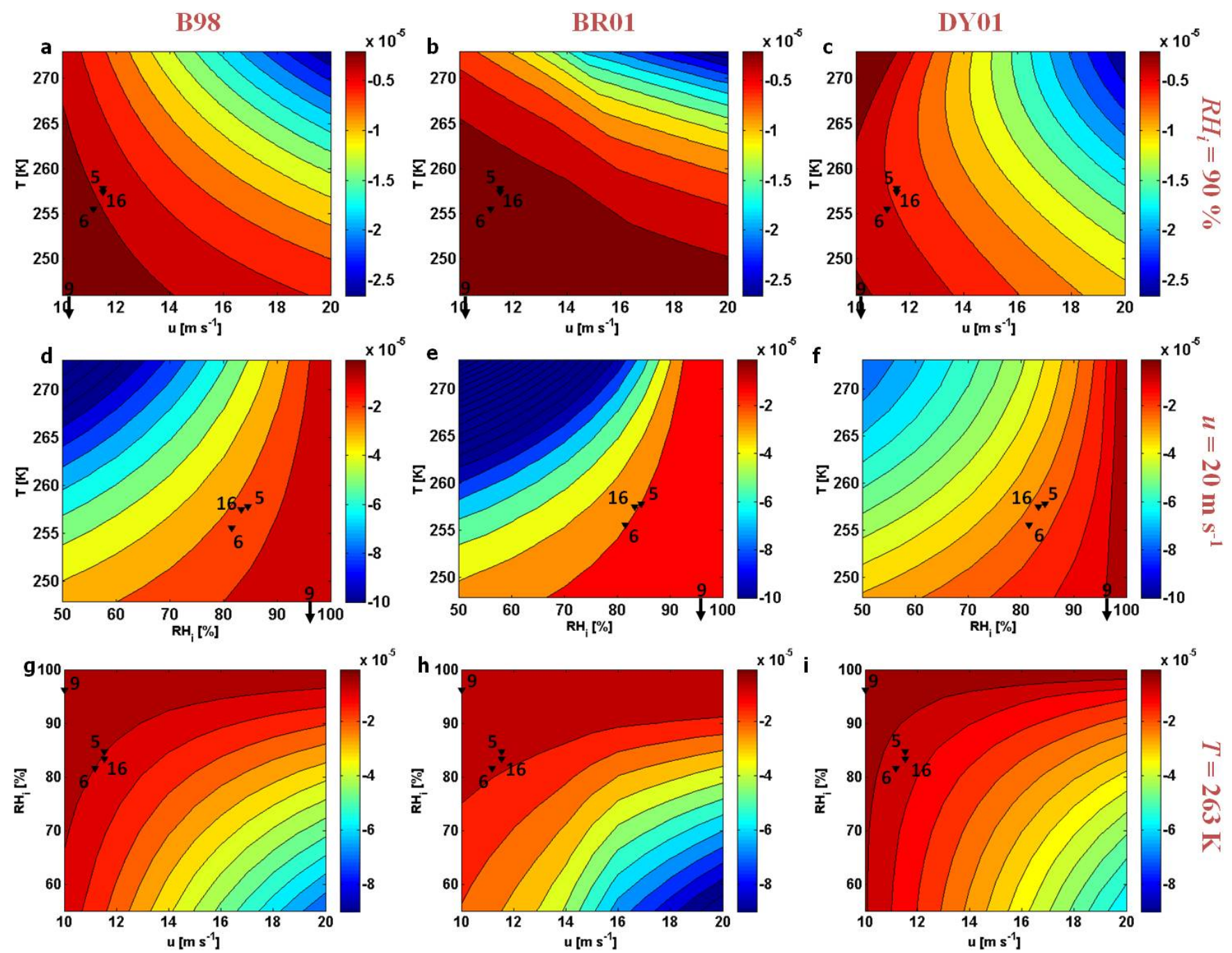

Fig. 8. $\mathrm{SU}_{\mathrm{ds}}$ rates $\left(\mathrm{kg} \mathrm{m}^{-2} \mathrm{~s}^{-1}\right)$ from 3 sensitivity experiments, with (a-c) relative humidity with respect to ice $\mathrm{RH}_{i}=90 \%$, $(\mathbf{d}-\mathbf{f})$ wind speed $u=20 \mathrm{~ms}^{-1}$, and (g-i) air temperature $T=263 \mathrm{~K}$, each one conducted for B98 (left panels), BR01 (central panels), and DY01 (right panels), respectively. Mean values for $\mathrm{RH}_{i}, u$ and $T$ were calculated for AWS 5, 6, 9 and 16 for snowdrift conditions and used to plot each station.

moisture content and inducing a more efficient mixing of the moisture input in the surface layer (Fig. 7c).

Positioning of the different AWSs relative to each other on the basis of average near-surface meteorological conditions during snowdrift-free conditions allows us to attribute the negative $\mathrm{SU}_{\mathrm{s}}$ anomaly at AWS 16 (Fig. 7). Indeed the average $\Delta T$ is much stronger at AWS 16 than at the other stations $(8.2 \mathrm{~K}$ at AWS 16 versus $2.4 \mathrm{~K}, 2.7 \mathrm{~K}$ and $1.3 \mathrm{~K}$ at AWS 5, 6 and 9, respectively). Consequently, as strong surface winds tend to destroy the near-surface $T$-inversion by enhancing vertical mixing (Ohata, 1985; Jonsson, 1995; Van den Broeke et al., 1999; Reijmer and Oerlemans, 2002), the low $\mathrm{SU}_{\mathrm{s}}$ at AWS 16 can be related to reduced katabatic influence at this station.

As for snowdrift sublimation, an extensive sensitivity analysis reveals that $\mathrm{SU}_{\mathrm{ds}}$ is predominantly limited by
$\mathrm{RH}_{i}$ (Fig. 8d-i), in agreement with findings from King et al. (1996) and Déry et al. (1998), but only when the ambient moisture content is high. Below a $\mathrm{RH}_{i}$ of about 70$80 \%, T$ and $u$ take over as the main controlling variables for $\mathrm{SU}_{\mathrm{ds}}$ (Fig. 8a-c). Higher $T$ allow for larger $q$-gradients to build across the drifting snow layer, while the impact of wind speed peaks at values just above the threshold for snow transport, when enhanced saltation drift density (Pomeroy and Gray, 1990) and stronger ventilation (Bintanja, 1998) are most effective. Hence, suppressed seasonality in $\mathrm{SU}_{\mathrm{ds}}$ (Fig. 3c-d) is probably due to higher $u$ balancing for lower $T$ during winter. Although minor differences exist, all three parameterisations show consistent behaviour.

Contrary to $\mathrm{SU}_{\mathrm{s}}$, visualisation of the mean atmospheric conditions during snowdrift (Fig. 8) does not lead to an understanding why $\mathrm{SU}_{\mathrm{ds}}$ rates at AWS 16 are two, respectively, 

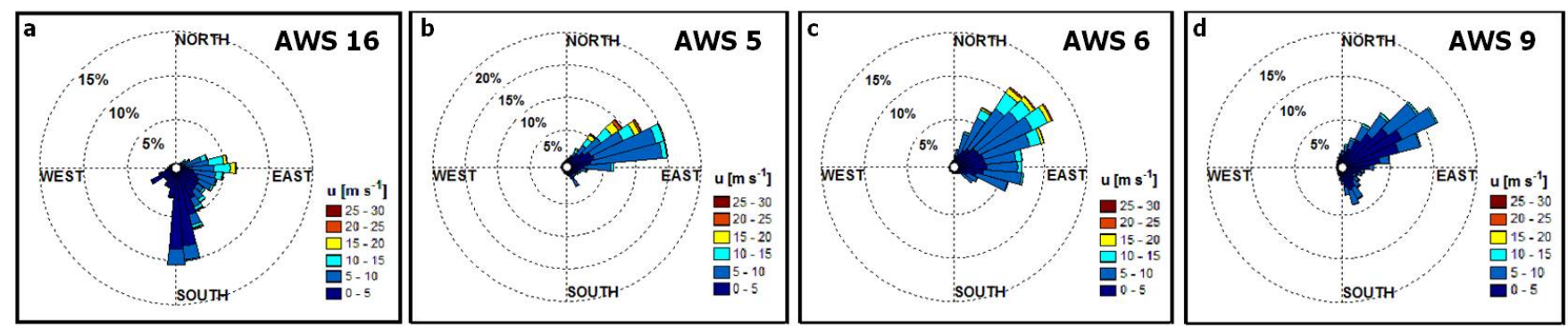

Fig. 9. Dominant wind directions measured at (a) AWS 16 - Princess Elisabeth, (b) AWS 5 - Wasa/Aboa, (c) AWS 6 - Svea Cross and (d) AWS 9 - Kohnen. The contribution of each wind speed class to a given wind direction is shown in the colour scale.

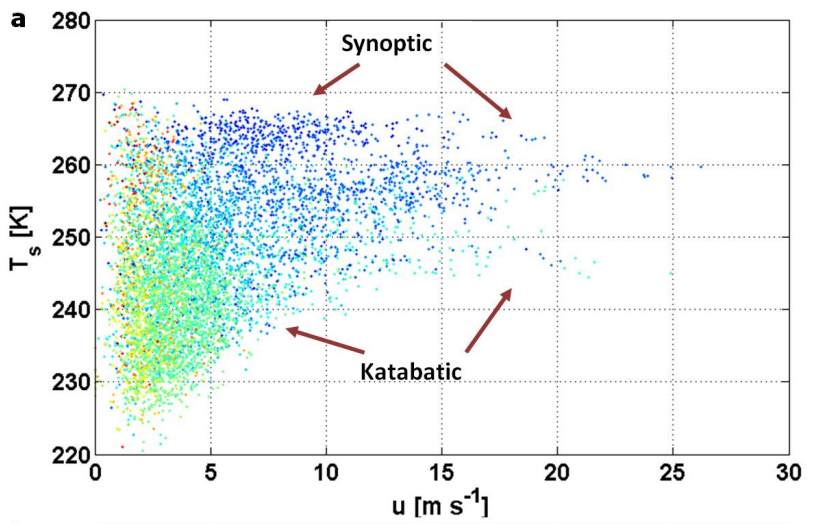

b

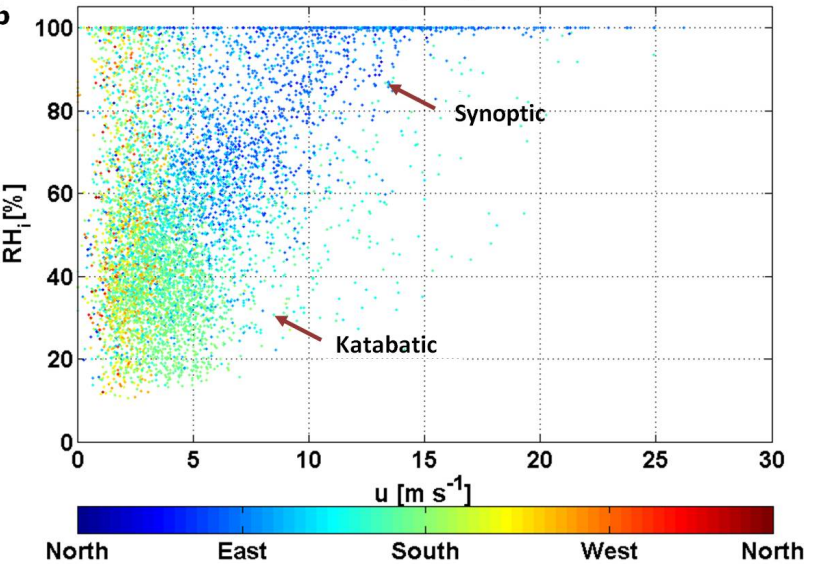

Fig. 10. Scatter plot of (a) surface temperature $T_{\mathrm{S}}$ and (b) relative humidity with respect to ice $\mathrm{RH}_{i}$ versus wind speed $u$ at AWS 16 . The colour of the scatter points represents the wind direction.

three times lower compared to AWS 5 and 6. Further investigation of the near-surface meteorology, described below, can however explain this difference.

Due to the specific geographic location of the station, wind fields observed at AWS 16 show a marked behaviour. Predominantly two wind speed regimes reign at AWS 16 (Fig. 9a). Most often, a S-SSE katabatic wind is blowing at low speed $\left(0-10 \mathrm{~m} \mathrm{~s}^{-1}\right)$. Strong katabatics are absent at the station, as they are blocked by the surrounding Sør Rondane mountains (Fig. 1b). On the other hand, during approx- imately $10-20 \%$ of the observation period, a strong E synoptic wind prevails at AWS 16. The highest wind speeds $\left(20-30 \mathrm{~m} \mathrm{~s}^{-1}\right)$ are all situated within this wind regime, and low wind speeds $\left(<5 \mathrm{~m} \mathrm{~s}^{-1}\right)$ blowing from this direction are very rare. Although a transition zone is present, generally both wind regimes coincide with a distinction in $T$ : while katabatics are usually associated with cold temperatures $(225-250 \mathrm{~K})$, the synoptic winds advect warmer air masses (255-267 K) (Fig. 10a). At high $u$, the difference is more pronounced, as the data cloud forks into a synoptic $(\sim 260 \mathrm{~K})$ and a katabatic $(247 \mathrm{~K})$ peak. Clearly the katabatic flow generally remains colder than the E maritime winds, even after adiabatic heating upon descend from the Antarctic Plateau (Fig. 1b). Finally, as the katabatic downflow also induces a drying of the near-surface air $\left(10 \%<\mathrm{RH}_{i}<60 \%\right)$, the contrast in $\mathrm{RH}_{i}$ with the nearly saturated maritime air masses $\left(80 \%<\mathrm{RH}_{i}<100 \%\right)$ is evident from the AWS 16 data (Fig. 10b).

Comparison to the wind regimes at AWS 5 and 6 allows to attribute the AWS $16 \mathrm{SU}_{\mathrm{ds}}$ anomaly. At AWS 5, the katabatic winds (ENE) dominate, with occasional high wind speeds coming from the synoptic regime (NE; Fig. 9b). The wind regime at AWS 6 appears comparable to AWS 16, taking into account that wind directions have backed by about $45^{\circ}$ (katabatic: SE; synoptic: NE; Fig. 9 c), probably due to local orography and a stronger Coriolis effect (Bintanja, 2000a). However, comparative histograms of the 2-hourly mean $u$, accompanied by a generalised extreme value (GEV) distribution fit to each dataset (Fig. 11a), reveal a marked difference between the different stations. Clearly, for $u$ ranging between $5 \mathrm{~m} \mathrm{~s}^{-1}$ and $15 \mathrm{~m} \mathrm{~s}^{-1}$, the probability of occurrence is much larger at AWS 5 and 6 compared to AWS 16 . Subsequent binning of $\mathrm{SU}_{\mathrm{ds}}$ on the basis of the wind speed data $\left(1 \mathrm{~m} \mathrm{~s}^{-1}\right.$ bin width, Fig. 11b), shows that the wind speed classes with the largest contribution to the total $\mathrm{SU}_{\mathrm{ds}}$ mass flux are $8-15 \mathrm{~m} \mathrm{~s}^{-1}$. While wind velocities below $8 \mathrm{~m} \mathrm{~s}^{-1}$ usually do not succeed in lifting particles from the surface, also strong winds (exceeding $15 \mathrm{~m} \mathrm{~s}^{-1}$ ) contribute only little to the total $\mathrm{SU}_{\mathrm{ds}}$, not only because they occur less often, but especially as they are usually associated with storm depressions (synoptic regime). In fact, given the maritime 

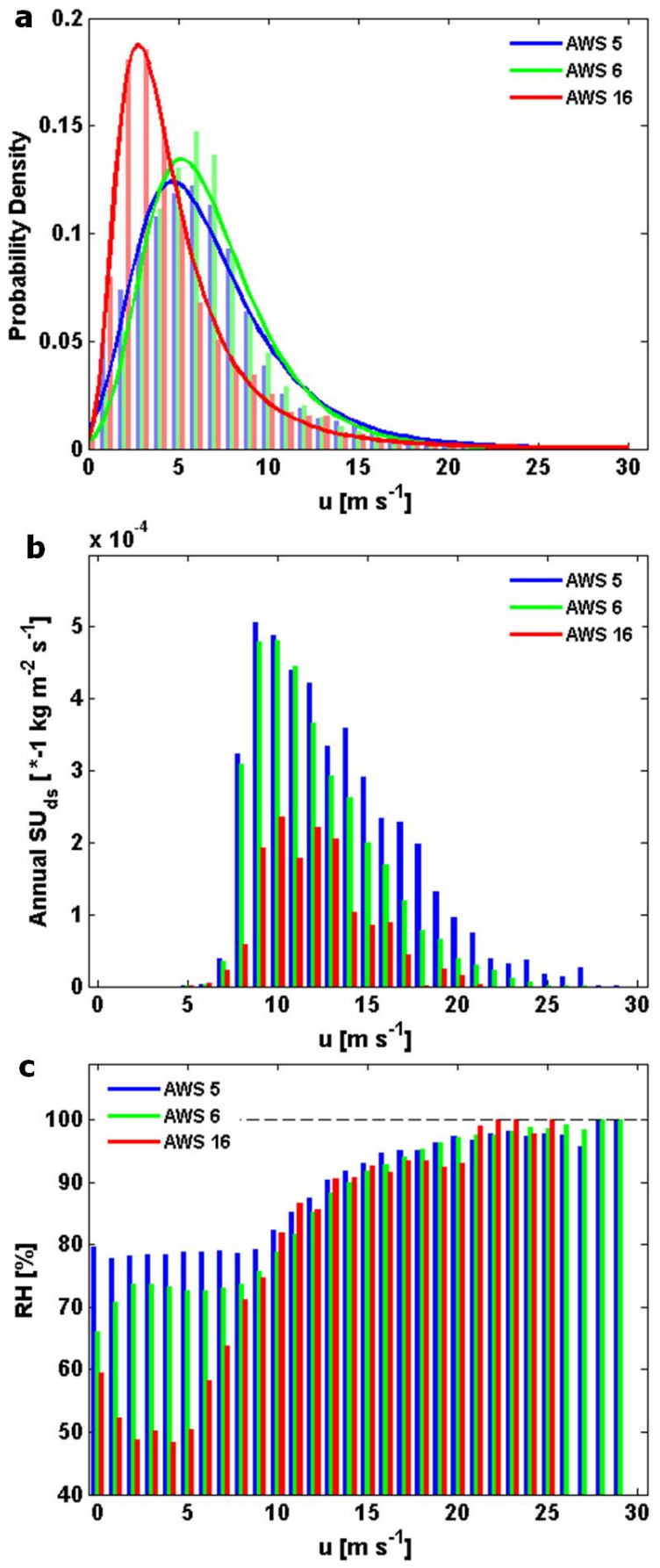

Fig. 11. (a) Histogram of 2-hourly mean wind velocity $u$, with the generalised extreme values (GEV) probability density function fitted to the data. From $u>25 \mathrm{~m} \mathrm{~s}^{-1}$ onwards, the three GEV curves overlay each other. Note that here the GEV distribution is preferred over the Weibull distribution, since $R^{2}$ is higher for the GEV fit $\left(0.97<R^{2}<0.99\right)$ than the Weibull fit $\left(0.91<R^{2}<0.95\right)$ at each location. (b) Total annual snowdrift sublimation $\mathrm{SU}_{\mathrm{ds}}$ for each wind speed bin (width $=1 \mathrm{~m} \mathrm{~s}^{-1}$ ). (c) Mean relative humidity with respect to ice $\mathrm{RH}_{i}$ for each wind speed bin (width $=1 \mathrm{~m} \mathrm{~s}^{-1}$ ). origin of these air masses and the precipitation which is regularly observed during such events (Gorodetskaya et al., 2012), associated $\mathrm{RH}_{i}$ values will be close to saturation and will therefore inhibit significant sublimation rates (Figs. 8di, 10). Binning the measured $\mathrm{RH}_{i}$ values on the basis of $u$ demonstrates that this saturation effect is present at each station (Fig. 11c).

On the contrary, moderate wind velocities $\left(8 \mathrm{~m} \mathrm{~s}^{-1}<u<\right.$ $15 \mathrm{~m} \mathrm{~s}^{-1}$ ) are strong enough to lift particles but still allow for significant ambient undersaturation. This wind regime, generally created by medium strength katabatic winds which dry upon descend from the Plateau, provides the ideal conditions for strong $\mathrm{SU}_{\mathrm{ds}}$ rates at all stations (Fig. 11a-c). The anomalously low $\mathrm{SU}_{\mathrm{ds}}$ rates at AWS 16 can now be understood: in essence, moderate wind velocities occur less often at AWS 16 compared to AWS 5 and 6, this due to orographic shielding of the former station (Fig. 11a). In fact, this shielding reduced the probability of snowdrift occurrence to $12 \%$ during the measurement period at AWS 16, whereas snowdrift occurred during $29 \%$, respectively, $23 \%$ of the time at AWS 5 and 6.

\section{Conclusions}

The goal of this study is to compare sublimation rates calculated from a newly installed automatic weather station (AWS) to existing time series in Dronning Maud Land and to explain the observed differences from a physical perspective. Remarkable differences were found between AWS 16 and two other katabatic stations in Dronning Maud Land. From February 2009 until February 2011, annual surface $\left(\mathrm{SU}_{\mathrm{s}}\right)$ and snowdrift sublimation $\left(\mathrm{SU}_{\mathrm{ds}}\right)$ rates at $\mathrm{AWS} 16$ were found to amount up to $-7 \mathrm{~mm}$ w.e. $\mathrm{yr}^{-1}$, respectively, $-10 \mathrm{~mm}$ w.e. $\mathrm{yr}^{-1}$. Both processes together have a significant influence on the surface mass balance at this station, by removing $10 \%$ of the total precipitation (PR) during the measurement period (assuming $\mathrm{ER}_{\mathrm{ds}}$ is negligible). However, sublimation rates at AWS 16 are 2 to 3 times lower compared to AWS 5 and 6 , where sublimation annually removes $22 \%$, respectively, $14 \%$ of all $\mathrm{PR}$ (assuming $\mathrm{ER}_{\mathrm{ds}}$ is negligible).

To account for this sublimation anomaly at AWS 16, a process study was undertaken in order to determine the controlling variables for surface and snowdrift sublimation. The specific humidity gradient, i.e. the combined effect of ambient $\mathrm{RH}_{i}$ and $\Delta T$, is predominant for both the sign and magnitude of $\mathrm{SU}_{\mathrm{s}}$ in Antarctica, whereas $T$ and $u$ only represent second order effects. Subsequently, it was found that the strong surface inversion, persisting throughout most of the year at AWS 16, strongly dampens $\mathrm{SU}_{\mathrm{s}}$ compared to AWS 5 and 6 . In contrast, the process study for sublimation during snowdrift events showed that $\mathrm{SU}_{\mathrm{ds}}$ is primarily limited by $\mathrm{RH}_{i}$ but only if the near-surface air is close to saturation. Below a $\mathrm{RH}_{i}$ of $\sim 70-80 \%, T$ and $u$ take over as the main 
controlling variables for $\mathrm{SU}_{\mathrm{ds}}$, with higher temperatures and stronger winds both allowing for enhanced $\mathrm{SU}_{\mathrm{ds}}$ rates. Surprisingly, application of these findings to the mean $T, \mathrm{RH}_{i}$ and $u$ conditions during snowdrift suggests comparable sublimation rates at all three AWSs. Hence, further investigation of the near-surface meteorology at AWS 16 was undertaken. This showed that not the mean conditions during snowdrift, but rather the markedly lower probability of occurrence of moderate, katabatic winds $\left(8 \mathrm{~m} \mathrm{~s}^{-1}<u<15 \mathrm{~m} \mathrm{~s}^{-1}\right)$ is responsible for the lower $\mathrm{SU}_{\mathrm{ds}}$ rates at AWS 16 . Precisely these wind speed classes are shown to contribute most to the total $\mathrm{SU}_{\mathrm{ds}}$ amounts, given their ability to lift particles while at the same time allowing for significant ambient undersaturation. To conclude, the sublimation anomaly at AWS 16 is the result of the twofold effect of the local orography, which protects the station from medium-strength katabatic winds and therewith (i) allows for a strong, dampening surface inversion to persist throughout most of the year, and (ii) reduces the occurrence of snowdrift by 50-70\% compared to nearby katabatic stations.

Acknowledgements. We would like to thank Stephen Déry and Mathias Rotach for the helpful discussions on the modelling of sublimation. This work was possible thanks to financial and logistic support from the Research Foundation - Flanders (FWO), The Belgian Science Policy Office (BELSPO) and the International Polar Foundation (IPF). For the simulations we used the infrastructure of the VSC - Flemish Supercomputer Center, funded by the Hercules Foundation and the Flemish Government - department EWI.

Edited by: E. Hanna

\section{References}

Anderson, P. S.: A method for rescaling humidity sensors at temperatures well below freezing, J. Atmos. Ocean. Tech., 11, 13881391, 1994.

Andreas, E. L.: A theory for the scalar roughness and the scalar transfer coefficients over snow and sea ice, Bound.-Lay. Meteorol., 38, 159-184, 1987.

Bamber, J. L., Gomez-Dans, J. L., and Griggs, J. A.: A new 1 km digital elevation model of the Antarctic derived from combined satellite radar and laser data - Part 1: Data and methods, The Cryosphere, 3, 101-111, doi:10.5194/tc-3-101-2009, 2009.

Bintanja, R.: The contribution of snowdrift sublimation to the surface mass balance of Antarctica, Ann. Glaciol., 27, 251-259, 1998.

Bintanja, R.: Mesoscale Meteorological Conditions in Dronning Maud Land, Antarctica, during Summer: A Qualitative Analysis of Forcing Mechanisms, J. Appl. Meteorol., 39, 2348-2370, 2000a.

Bintanja, R.: Snowdrift Sublimation in a Katabatic Wind Region of the Antarctic Ice Sheet, J. Appl. Meteorol., 40, 1955-1966, $2000 \mathrm{~b}$.
Bintanja, R.: Snowdrift suspension and atmospheric turbulence. Part I: Theoretical background and model description, Bound.Lay. Meteorol., 95, 343-368, 2000c.

Bintanja, R.: Surface heat budget of Antarctic snow and blue ice: Interpretation of spatial and temporal variability, J. Geophys. Res., 105, 387-411, doi:10.1029/2000JD900356, 2000d.

Bintanja, R.: Modelling snowdrift sublimation and its effect on the moisture budget of the atmospheric boundary layer, Tellus A, 53, 215-232, 2001a.

Bintanja, R.: Modification of the wind speed profile caused by snowdrift: results from observations, Q. J. Roy. Meteor. Soc., 127, 2417-2434, 2001b.

Bintanja, R. and Reijmer, C. H.: A simple parameterization for snowdrift sublimation over Antarctic snow surfaces, J. Geophys. Res., 106, 739-748, doi:10.1029/2000JD000107, 2001.

Bintanja, R. and Van den Broeke, M. R.: The surface energy balance of Antarctic snow and blue ice, J. Appl. Meteorol., 34, 902-926, 1995.

Braaten, D. A.: Direct measurements of episodic snow accumulation on the Antarctic polar plateau, J. Geophys. Res., 105, 119128, doi:10.1029/2000JD900099, 2000.

Brandt, R. E. and Warren, S. G.: Solar-heating rates and temperature profiles in Antarctic snow and ice, J. Glaciol., 39, 99-110, 1993.

Bromwich, D. H., Guo, Z., Bai, L., and Chen, Q.: Modeled Antarctic Precipitation - Part I: Spatial and Temporal Variability, J. Clim., 17, 427-447, 2004.

Budd, W. F., Dingle, R. J., and Radok, U.: The Byrd Snow Drift Project: outline and basic results, in: Studies in Antarctic meteorology, edited by: Rubin, M. J., American Geophysical Union, Washington D.C., 1966.

Curry, J. A. and Webster, P. J.: Thermodynamics of Atmospheres and oceans, Academic Press, London, UK, 1999.

Denby, B. and Greuell, W.: The use of bulk and profile methods for determining surface heat fluxes in the presence of glacier winds, J. Glaciol., 46, 445-452, 2000.

Déry, S. J. and Taylor, P. A.: Some aspects of the interaction of blowing snow with the atmospheric boundary layer, Hydrol. Process., 10, 1345-1358, 1996.

Déry, S. J. and Yau, M. K.: A bulk blowing snow model, Bound.Lay. Meteorol., 93, 237-251, 1999.

Déry, S. J. and Yau, M. K.: Simulation of blowing snow in the Canadian Arctic using a double-moment model, Bound.-Lay. Meteorol., 99, 297-316, 2001.

Déry, S. J. and Yau, M. K.: Large-scale mass balance effects of blowing snow and surface sublimation, J. Geophys. Res., 107(D23), 4679-4696, doi:10.1029/2001JD001251, 2002.

Déry, S. J., Taylor, P. A., and Xiao, J.: The thermodynamic effects of sublimating, blowing snow in the atmospheric boundary layer, Bound.-Lay. Meteorol., 89, 251-283, 1998.

Dyer, A. J.: A review of flux-profile relationships, Bound.-Lay. Meteorol., 7, 363-372, 1974.

Essery, R., Li, L., and Pomeroy, J.: A distributed model of blowing snow over complex terrain, Hydrol. Process., 13, 2423-2438, 1999.

Frezzotti, M., Pourchet, M., Flora, O., Gandolfi, S., Gay, M., Urbini, S., Vincent, C., Becagli, S., Gragnani, R., Proposito, M., Severi, M., Traversi, R., Udisti, R., and Fily, M.: New estimations of precipitation and surface sublimation in East Antarctica from snow accumulation measurements, Clim. Dynam., 23, 803-813, 
doi:10.1007/s00382-004-0462-5, 2004.

Gallée, H.: Simulation of blowing snow over the Antarctic ice sheet, Ann. Glaciol., 26, 203-206, 1998.

Gallée, H., Guyomarc'h, G., and Brun, E.: Impact of snowdrift on the Antarctic ice sheet surface mass balance: possible sensitivity to snow-surface properties, Bound.-Lay. Meteorol., 99, 1-19, 2001.

Giesen, R. H., Van den Broeke, M. R., Oerlemans, J., and Andreassen, L. M.: Surface energy balance in the ablation zone of Midtdalsbreen, a glacier in southern Norway: interannual variability and the effect of clouds, J. Geophys. Res., 113, D21111, doi:10.1029/2008JD010390, 2008.

Gorodetskaya, I. V., Van Lipzig, N. P. M., Van den Broeke, M. R., Boot, W., Reijmer, C. H., Mangold, A., Kneifel, S. Crewell, S., and Schween, J.: Ground-based observations of cloud properties, precipitation and meteorological conditions at Princess Elisabeth station in Dronning Maud Land, Antarctica, BPRC Technical Report 2010-01. Byrd Polar Research Center at Ohio State University, Columbus, Ohio, USA, 2010.

Gorodetskaya, I. V., Van Lipzig, N. P. M., Van den Broeke, M. R., Boot, W., and Reijmer, C. H.: Meteorological regimes and accumulation patterns at Utsteinen, Dronning Maud Land, East Antarctica: Analysis of two contrasting years, J. Geophys. Res., in review, 2012.

Holtslag, A. A. M. and De Bruin, H. A. R.: Applied modeling of the nighttime surface energy balance over land, J. Appl. Meteorol., 27, 689-704, 1988.

Jaeger, L.: Monaskarten des Niederschlags fur die ganze Erde, Report of the German Weather Service 139(18), Offenbach, Germany, 33 pp., 1976.

Jonsson, S.: Synoptic forcing of wind and temperature in a large cirque $300 \mathrm{~km}$ from the coast of East Antarctica, Antarct. Sci., 7, 409-420, 1995.

King, J. C.: Longwave atmospheric radiation over Antarctica, Antarct. Sci., 8, 105-109, 1996.

Kuipers Munneke, P., van den Broeke, M. R., Reijmer, C. H., Helsen, M. M., Boot, W., Schneebeli, M., and Steffen, K.: The role of radiation penetration in the energy budget of the snowpack at Summit, Greenland, The Cryosphere, 3, 155-165, doi:10.5194/tc-3-155-2009, 2009.

Lenaerts, J. T. M. and Van den Broeke, M. R.: Regional climate modeling of drifting snow in Antarctica - Part 2: Results, J. Geophys. Res., 117, D05109, doi:10.1029/2010JD015419, 2012.

Lenaerts, J. T. M., Van den Broeke, M. R., Déry, S. J., KönigLanglo, G., Etema, J., and Munneke, P. K.: Modelling snowdrift sublimation on an Antarctic ice shelf, The Cryosphere, 4, 179190, doi:10.5194/tc-4-179-2010, 2010.

Li, L. and Pomeroy, J. W.: Estimates of threshold wind speeds for snow transport using meteorological data, J. Appl. Meteorol., 36, 205-213, 1997.

Liston, G. E. and Elder, K.: A Distributed Snow-Evolution Modeling System (SnowModel), J. Hydrometeorol., 7, 1259-1267, 2006.

Liston, G. E. and Sturm, M.: A snow-transport model for complex terrain, J. Glaciol., 44, 498-516, 1998.

Lythe, M. B. and Vaughan, D. G.: BEDMAP: a new ice thickness and subglacial topographic model of Antarctica, J. Geophys. Res., 106, 335-351, doi:10.1029/2000JB900449, 2001.
Mann, G. W.: Surface Heat and Water Vapour Budgets over Antarctica, Ph.D. thesis, University of Leeds, UK, 1998.

Mann, G. W., Anderson, P. S., and Mobbs, S. D.: Profile measurements of blowing snow at Halley, Antarctica, J. Geophys. Res., 105, 491-508, 2000.

Mobbs, S. D. and Dover, S. E.: Numerical Modelling of Blowing Snow, Antarctic Special Topic, 55-63, 1993.

Ohata, T.: Heat balance at the snow surface in a katabatic wind zone, east Antarctica, Ann. Glaciol., 6, 174-177, 1985.

Pattyn, F., Matsuoka, K., and Berte, J.: Meteorological conditions in the vicinity of the Princess Elisabeth Station, Antarctica, Antarct. Sci., 22, 79-85, doi:10.1017/S0954102009990344, 2009.

Pomeroy, J. W. and Gray, D. M.: Saltation of snow, Water Resour. Res., 26, 1583-1594, 1990.

Pomeroy, J. W., Gray, D. M., and Landine, P. G.: The Prairie Blowing Snow Model: Characteristics, Validation, Operation, J. Hydrol., 144, 165-192, 1993.

Reijmer, C. H. and Oerlemans, J.: Temporal and spatial variability of the surface energy balance in Dronning Maud Land, East Antarctica, J. Geophys. Res., 107, 4759-4770, doi:10.1029/2000JD000110, 2002.

Reijmer, C. H. and Van den Broeke, M. R.: Temporal and spatial variability of the surface mass balance in Dronning Maud Land, Antarctica, as derived from automatic weather stations, J. Glaciol., 49, 512-520, doi:10.3189/172756503781830494, 2003.

Schmidt, R. A.: Vertical profiles of wind speed, snow concentration and humidity in blowing snow, Bound.-Lay. Meteorol., 23, 223246, 1982.

Schmidt, R. A.: Transport rate of drifting snow and the mean wind speed profile, Bound.-Lay. Meteorol., 34, 213-241, 1986.

Schwerdtfeger, W.: Weather and climate of the Antarctic, Elsevier, Amsterdam, The Netherlands, 1984.

Takahashi, S., Endoh, T., Azuma, N., and Meshida, S.: Bare ice fields developed in the inland part of Antarctica, Proceedings of the NIPR Symposium on Polar Meteorology and Glaciology, Tokyo, Japan, 12-13 June 1990, 128-139, 1992.

Takahashi, S., Ageta, Y., Fujii, Y., and Wanatabe, O.: Surface mass balance in east Dronning Maud Land, Antarctica, observed by Japanese Antarctic Research Expeditions, Ann. Glaciol., 20, 242-248, 1994.

Uematsu, T.: Numerical study on snow transport and drift formation, Ann. Glaciol., 18, 135-141, 1993.

Van As, D., Van den Broeke, M. R., Reijmer, C. H., and Van de Wal, R. S. W.: The summer surface energy balance of the high Antarctic Plateau, Bound.-Lay. Meteorol., 115, 289-317, 2005.

Van de Berg, W. J., Van den Broeke, M. R., Reijmer, C. H., and Van Meijgaard, E.: Reassessment of the Antarctic surface mass balance using calibrated output of a regional atmospheric climate model, J. Geophys. Res., 111, D11104, doi:10.1029/2005JD006495, 2006.

Van den Broeke, M. R. and Van Lipzig, N. P. M.: Changes in Antarctic temperature, wind and precipitation in response to the Antarctic Oscillation, Ann. Glaciol., 39, 119-126, 2004.

Van den Broeke, M. R., Winther, J.-G., Isaksson, E., Pinglot, J. F., Karlof, L., Eiken, T., and Conrads, L.: Climate variables along a traverse line in Dronning Maud Land, East Antarctica, J. Glaciol., 45, 295-302, 1999. 
Van den Broeke, M. R., Reijmer, C. H., and Van de Wal, R. S. W.: A study of the surface mass balance in Dronning Maud Land, Antarctica, using automatic weather stations, J. Glaciol., 50, 565-582, 2004a.

Van den Broeke, M. R., Van As, D., Reijmer, C. H., and Van de Wal, R. S. W.: The surface radiation balance in Antarctica as measured with automatic weather stations. J. Geophys. Res., 109, 1-17, doi:10.1029/2003JD004394, 2004b.

Van den Broeke, M. R., Reijmer, C. H., Van As, D., Van de Wal, R., and Oerlemans, J.: Seasonal cycles of Antarctic surface energy balance from automatic weather stations, Ann. Glaciol., 41, 131139, 2005.

Van den Broeke, M. R., Smeets, C. J. P. P., and Van de Wal, R. S. W.: The seasonal cycle and interannual variability of surface energy balance and melt in the ablation zone of the west Greenland ice sheet, The Cryosphere, 5, 377-390, doi:10.5194/tc-5-377-2011, 2011.

Van Lipzig, N. P. M.: Wind, in: Encyclopedia of the Antarctic, edited by: Riffenburgh, B., Routledge, Oxon, UK, 1084-1086, 2007.

Van Lipzig, N. P. M., Van Meijgaard, E., and Oerlemans, J.: Temperature sensitivity of the Antarctic surface mass balance in a regional atmospheric climate model, J. Climate, 15, 2758-2774, 2002a.
Van Lipzig, N. P. M., Van Meijgaard, E., and Oerlemans, J.: The spatial and temporal variability of the surface mass balance in Antarctica: results from a regional atmospheric climate model, Int. J. Climatol., 22, 1197-1217, doi:10.1002/joc.798, 2002 b.

Van Lipzig, N. P. M., King, J. C., Lachlan-Cope, T. A., and Van den Broeke, M. R.: Precipitation, sublimation, and snowdrift in the Antarctic Peninsula region from a regional atmospheric model, J. Geophys. Res., 119, D24106, doi:10.1029/2004JD004701, 2004.

Vaughan, D. G., Bamber, J. L., Giovinetto, M., Russell, J., and Cooper, A. P. R.: Reassessment of net surface mass balance in Antarctica, J. Climate, 12, 933-946, 1999.

Wamser, C. and Lykossov, V. N.: On the friction velocity during blowing snow, Contrib. Atmos. Phys., 68, 85-94, 1995.

Wendler, G., Stearns, C., Weidner, G. A., and Dargaud, G.: On the extraordinary katabatic winds of Adelie Land, J. Geophys. Res., 102, 4463-4474, doi:10.1029/96JD03438, 1997.

Xiao, J., Bintanja, R., Dery, S. J., Mann, G. W., and Taylor, P. A.: An intercomparison among four models of blowing snow, Bound.Lay. Meteorol., 97, 109-135, 2000. 